\title{
Effects of Traditional and Modern Post-Harvest Withering Pro- cesses on the Composition of the Vitis v. Corvina Grape and the Sensory Profile of Amarone Wines
}

\author{
Tomasi D. ${ }^{1}$, Lonardi A. ${ }^{2}$, Boscaro D. ${ }^{1}$, Nardi T. ${ }^{1}$, Mayr Marangon C. ${ }^{4}$, De Rosso M. ${ }^{1}$, Flamini R., ${ }^{1}$ Lovat L. ${ }^{1}$, \\ Mian G. ${ }^{1-3^{*}}$ \\ 1 Council for Agricultural Research and Economics - Research Centre for Viticulture and Oenology CREA-VE \\ Viale XXVIII aprile 26, 31015 Conegliano, TV, Italy. lorenzo.lovat@crea.gov.it (L.L.); \\ tiziana.nardi@crea.gov.it (T.N.), davide.boscaro@crea.gov.it (D.B.), diego.tomasi@crea.gov.it (D.T.), ric- \\ cardo.flamini@crea.gov.it (R.F.), mirko.derosso@crea.gov.it (M.DR.) \\ 2 Bertani Domains Società Agricola A R.L., Via Asiago 1, 37023 Grezzana (VR), andrea.lonardi@bertani.net \\ (A.L.) \\ 3 Department of AgriFood, Environmental and Animal Sciences, University of Udine, Via delle Scienze 206, \\ 33100 Udine, Italy; giovanni.mian@uniud.it (G.M.). ORCID: https://orcid.org/0000-0002-3597-5014 \\ 4 Department of Agronomy, Food, Natural Resources, Animals and Environment (DAFNAE), \\ University of Padova, Viale dell'Università 16, 35020 Padova, Italy. christine.marangon@unipd.it (C.M.M.) \\ * Correspondence: giovanni.mian@uniud.it
}

\begin{abstract}
In the Valpolicella area (Verona - Italy) Vitis vinifera cv. Corvina is the main grape variety used to produce Amarone wine. Before starting the winemaking process, the Corvina grapes are stored in a withering (i.e., dehydrating) warehouse until about $30 \%$ of the berry weight is lost (WL). This practice is followed to have the chemical metabolites concentrate in the berry and enrich the Amarone wine in aroma and antioxidant compounds. In compliance with the guidelines and strict Amarone protocol set by the Consorzio of Amarone-Valpolicella, withering must be carried out by setting the grapes in a suitable environment, either under controlled relative air humidity (RH) conditions and wind speed (WS) - no temperature modification is to be applied - or, following the traditional methods, in open-air natural environmental conditions. In general, the two processes have different dehydration kinetics due to the different conditions in terms of temperature, $\mathrm{RH}$, and WS, which affect the accumulation of sugars and organic acids and the biosynthesis of secondary metabolites such as stilbenes and glycoside aroma precursors. For this study, the two grapewithering processes were carried out under controlled (C) and not-controlled (NC) conditions and the final compositions of the Corvina dried grapes were compared also to evaluate the effects on the organoleptic characteristics of Amarone wine. The findings highlighted differences between the two processes mainly in terms of the secondary metabolites of the dried grapes, which affect the organoleptic characteristics of Amarone wine.
\end{abstract}

Keywords: post-harvest; grape; wine; withering; stilbenes; aroma; Amarone; Corvina

\section{Introduction}

Wine grapes are generally harvested at the proper technical ripening stage, which is when the major chemical ripening parameters $(\mathrm{pH}$, acidity, soluble sugars, polyphenols and aromatic compounds) meet the oenological requirements of each type of wine, according to the oenological goal set by the winemakers [1]. Indeed, some characteristic wines (sweet or dry) are produced by drying the harvested grapes in the open air 
(Moscato di Pantelleria) or by storing them in withering (dehydration) chambers before vinification, to achieve a weight loss (WL) of around 30\% (Pedro Ximenez of MontillaMoriles, Riesling, Commandaria of Cipro, Vin Santo di Santorini, French Souternes, Valpolicella Amarone).

Worldwide, Amarone is considered one of the most important Italian wines (15 million $750 \mathrm{ml}$ bottles, with an average commercial price of $62 \mathrm{USD} /$ bottle - Consortium for the protection of DOP Valpolicella Wine, 2019 data provided by Siquria). Amarone is produced from three native varieties: Corvina, Corvinone, and Rondinella (Consorzio Valpolicella, 2010), however, withered Corvina grapes are still the main variety used to craft this wine [2]. Corvina is a native variety of the Verona area; the wine it gives is characterised by hints of cherry, bitter almond, blossom aromas, and refreshing acidity; nevertheless, it lacks anthocyanins and has a moderate content of skin tannins. The withering process, in this sense, has been selected over the decades to concentrate and enrich the berry and wine composition.

The grape drying process involves two simultaneous transfer phenomena: i) heat (energy) transferred from the environment to the bunches and ii) water (mass) transfer from the inside to the outer surface of the berries, followed by evaporation. The drying conditions influence the properties of the resulting grapes and wines; slow drying at a low temperature $(\mathrm{T})$ and aeration rate $(\mathrm{W})$ and higher relative humidity levels $(\mathrm{RH})$, provides more harmonious wines [3]. Whereas, fast drying (high T, low RH, high W), could lead to wines with unbalanced aromatic profiles [4]. Drying also causes cell damage and alters the overall structure of the berry due to the loss of moisture and consequent berry sanitary issues [5]. As a consequence of berry water loss, the skin/pulp ratio increases, moreover, withering causes compositional changes in the phenolic and aromatic composition to an extent that is variable depending on the specific drying conditions [6]. Biochemical changes have also been described in berries dehydrated in ventilated chambers, deriving from environmental parameters and endogenous factors (genotype) [7].

The most marked effect occurs on sugars. Their increase is mainly due to a concentration effect, however, the composition and nature of the sugars change throughout the drying process, particularly in terms of the glucose/fructose ratio variations [8]. The change in the glucose/fructose ratio in this phase is mainly due to respiration [9] which preferably uses glucose as a substrate. Organic acidity, as for sugars, during the drying process is influenced by the concentrative aspect and both malic and tartaric acid are affected by the metabolic respiration and precipitation processes. These changes may have a different intensity depending on the organic acid considered, and the stage and intensity within the dehydration process. It is reported that there are slight increases in the total acidity mainly due to the concentration of tartaric acid [10] as well as a slight decrease in malic acid [11]. Specifically, during the drying process, the sugar/acid ratio varies significantly, and this is linked to the marked concentration of sugars [12].

Alongside the primary metabolism compounds, the secondary metabolites, mainly present in the hypodermal layer of the berry skin and that affect colour, flavour and aroma of the wine, also need to be considered $[13,14]$. The withering process affects the development of dehydration-related aromas and polyphenolic compounds [6]. Following harvest, as the grape berry is metabolically active until cell death, it reacts to endogenous and exogenous stresses such as dehydration. In the early stages of the drying process, there is an enrichment of polyphenols [15-17] due to new synthesis, confirmed by the increase in the transcripts of their biosynthetic pathway [18]. At a later stage, an oxidative process of the polyphenols takes place, leading to a depletion of many of them [16,19]. And while withering does induce a general decrease of 
polyphenols, such as anthocyanins, flavanols, procyanidins and glycoside flavonols $[19,20]$, an increment of other polyphenols, such as trans-resveratrol $\left(3,5,4^{\prime}-\right.$ trihydroxystilbene), taxifolin, quercetin, some methoxylated flavanones and acylated anthocyanins, was observed $[9,19,20,21]$.

Regarding polyphenols, the synthesis of stilbenes produced as a response to abiotic cell stress (i.e., trans-resveratrol, viniferins, cis- and trans-piceid) is crucial for the development of the nutraceutical properties of grapes and wine [15]. In particular, many studies have demonstrated the antioxidant, anti-inflammatory, and cardioprotective properties of trans-resveratrol, alongside its ability to inhibit platelet aggregation and antimutagenic and antiproliferative effects.

Likewise, piceatannol (3,4,3',5'-tetrahydroxy-trans-stilbene) has been shown to block LMP2A, a viral protein-tyrosine kinase associated with leukaemia, non-Hodgkin's lymphoma, and other diseases associated with the EBV virus, which also acts on human melanoma cells [22]. The withering process also affects the volatile organic compounds (VOCs) and their glycoside precursors in grapes [23,24]. Indeed, following harvest, the dehydrated berry VOCs increase not only as a concentration effect but also as a consequence of an active process [25]. It was observed that a dehydration temperature of above $30^{\circ} \mathrm{C}$ drastically reduces the share of primary and varietal aroma compounds (e.g., terpenes and norisoprenoids), which instead are maintained and concentrated slowly at temperatures of around $20^{\circ} \mathrm{C}$ and up to $40 \%$ of berry water loss [26]. Studies on aroma composition carried out during the dehydration of Pinot noir [27] and Pedro Ximenez [28] grapes showed that the aroma profiles are affected both qualitatively and quantitatively due to the development of new odorous compounds [23]. These new compounds confer notes of jam, raisins, plums, morello cherries, and almond. The main grape aroma compounds of Amarone wines belong to chemical classes of $\mathrm{C}_{13-}$ norisoprenoids, terpenes, benzenoids, furans, and aliphatic alcohols [29].

Current Amarone withering techniques require an average of 2.5 months (as stated by law, grape crushing cannot be done before $1^{\text {st }}$ December, MIIPAF; Reg, $n^{\circ} 558533 / 2019$ ) [30], yielding a final product that is richer in sugars, polyphenols, and aromatic compounds. In the past, the Amarone withering was carried out by setting the grapes on particular wooden trays known as arelle, inside dehydration chambers not provided with any climatic control; nowadays, air humidity and ventilation can easily be controlled (no extra temperature conditioning is allowed by the Amarone production regulations) [30]. Indeed, artificial environment conditioning provides faster withering and allows to achieve healthy dried grapes, though, it seems to be stressful for the berries [7]. Studies focusing on post-harvest events have confirmed that functional biochemical and molecular changes continue within the berries reflecting the environmental conditions of post-harvest ripening and/or senescence [18,31,32]. Moreover, Ferrarini [33] conducted a study to investigate the best timing for harvest and withering to achieve a more aromatic Amarone wine.

The primary purpose of this work is to compare natural and artificial Corvina withering processes to assess their effect on dried grape chemical composition and peculiar wine organoleptic evaluations. This aspect is particularly interesting for the few wineries that still adopt the traditional drying synthesis to pursue a true-to-varietal character and vintage-related wine. 


\section{Materials and Methods}

\subsection{Experimental setup}

The experimental data were collected during 2016 and 2017. The vineyard was selected the in Valpolicella classic area (Novare locality in the Negrar municipality, Verona) owned by a worldwide renowned Amarone wine producer, Bertani. The vine training system adopted was Guyot with a plant density of 4,444 vines per hectare; the variety raised was Corvina, clone ISV-CV48 grafted onto Kober 5 bb, grown predominantly in calcareous soil. Corvina was chosen as it is commonly the main variety for Amarone wine production. Harvest, following local tradition, was scheduled to take place ten days before the standard harvest period for Valpolicella fresh wine, occurring on 17 September in 2016 and on 6 September in 2017. In order to preserve their healthy status, the carefully selected grapes were placed in plastic trays - in the case of the modern warehouse drying process - and in the traditional arelle (wooden trays) to wither the grapes under natural conditions. In modern warehouses, air dehumidifiers maintained the air humidity between 60 and 70\% (optimal range for grape dehydration) and fans were used to provide airflow through the drying trays. Instead, the natural and traditional dehydration process took place without any air humidity control system or mechanical airflow: the warehouse supervisor was in charge of opening or closing the windows to enable the high-moisture air to escape and the dry, fresh air to flow inside the drying chamber. In this study, the two withering chambers (C: controlled, NC: notcontrolled environment) were close to each other on the winery premises (Bertani), though the NC chamber stood closer to the bottom of the hill where air movement is enhanced by the natural breeze which assists the discharge of the humid air from the chamber through the open windows. Berry chemical composition was analysed at four different stages: i) T0 fresh berry, ii) $-10 \%$ of berry water loss (WL), iii) $-20 \%$ WL, iv) $30 \% \mathrm{WL}$.

\subsection{Withering environmental conditions}

The climatic conditions in both environments, C and NC, were measured. Specifically, temperature and humidity were measured using air sensors (Lascar Electronics EL USB - 2) located in each environment of study: four sensors per drying chamber, two in contact with the withering grapes and two $50 \mathrm{~cm}$ above the grapes. The daily values recorded were the average of the measurements collected every 15 minutes. The outdoor climatic conditions were measured by the weather station belonging to Avepa (Avepa.it) located in the Negrar area. In 2016, due to contingent technical problems during data download, the initial climatic records (first ten days) collected in the withering chamber were lost.

\subsection{Kinetics of withering and grape samples}

The kinetics of the withering process was evaluated by measuring the post-harvest weight loss; in the NC and C treatments, where values are expressed as the percentage (\%) of weight loss during withering. Specifically, data were taken by weighing two arella trays (about $250 \mathrm{~kg}$ of grapes) in the case of the natural environment treatment and two pallets of trays (around $200 \mathrm{~kg}$ of grapes) as regards to the controlled environment. The arella trays and the pallets were chosen from two representative positions within the drying chambers. As last consideration, we report that these values does not come from replicates, since they represent the whole weight of a tray (with hundred bunches), only distinguished in C and NC. 
For both drying processes (C and NC), at harvest time (T0) and during withering (-10\% $\mathrm{WL},-20 \% \mathrm{WL}$, and $-30 \% \mathrm{WL})$, three samples of grapes weighing $1.0 \mathrm{~kg}$ each were collected to determine the berry chemical composition. The samples were obtained from several portions of the grape bunches stored on the selected trays and pellets.

\subsection{Accumulation of sugars and acids}

The total soluble sugars in the berries were quantified using an ATAGO PR-32 digital refractometer (0-32\%) and expressed in Total Soluble Sugars (TSS), Brix degree; in the same samples, the organic acid profile of the berries (specifically tartaric and malic acids, expressed in $\mathrm{g} / \mathrm{L}$ ), was determined by high-pressure liquid chromatography (HPLC Agilent 1220 infinity). The samples for HPLC were prepared taking $250 \mu \mathrm{L}$ of grape must diluted 1:50 with distilled water. The sample was then filtered through a $0.2 \mu \mathrm{m}$ filter and analysed. The grape must samples were prepared by pressing three subsamples of $250 \mathrm{~g}$ of berries.

\subsection{Accumulation of colouring substances}

Among the berry skin flavonoids, those belonging to the anthocyanins class are the most interesting in terms of direct feedback on the characteristics of a wine. Following the method described by Di Stefano [11], in 30-berry samples per withering process, the total flavonoids and total anthocyanins were quantified. The values were expressed in $\mathrm{mg} / \mathrm{kg}$ of grapes.

\subsection{Gas chromatography/mass spectrometry analysis of volatile compounds}

The glycosidic bound aroma compounds were analysed by GC/MS after enzymatic hydrolysis according to the methods by Di Stefano (1991) e Mateo et al. and summarized by Flamini and Traldi [34-36]. The skins of 100 berries were separated from the pulp and extracted with $35 \mathrm{~mL}$ of methanol for $4 \mathrm{~h}$ in the dark. The extract was homogenized using an Ultra-Turrax and centrifuged. The volume of the supernatant was adjusted to $250 \mathrm{~mL}$ with water, and the solution was treated with $2 \mathrm{~g}$ of insoluble poly(vinylpyrrolidone) (PVP) to reduce the polyphenolic content. Also, the pulp was homogenized and centrifuged, and the volume was adjusted to $250 \mathrm{~mL}$. The solutions were treated with $75 \mathrm{mg}$ of pectolytic enzyme for $4 \mathrm{~h}$ at room temperature to release the free aroma compounds. Following the addition of 1-heptanol as internal standard, the aglycones were isolated using an SPE $10 \mathrm{~g} \mathrm{C} 18$ cartridge (Waters Corporation, Milford, MA) previously activated by successive passages of $30 \mathrm{~mL}$ dichloromethane, $30 \mathrm{~mL}$ methanol, and $30 \mathrm{~mL}$ water. Salts, sugars, and other polar compounds were removed by washing the cartridge with $50 \mathrm{~mL}$ of water, and the fraction containing the free compounds was recovered using $50 \mathrm{~mL}$ of dichloromethane. The solution was concentrated to $2-3 \mathrm{~mL}$ by distillation using a $40 \mathrm{~cm}$ length Vigreux column then to 200 $\mu \mathrm{L}$ under a nitrogen flow prior to perform GC/MS analysis.

Gas chromatography/mass spectrometry (GC/MS) analysis was performed using a 6850 gas chromatography system by Agilent Technologies (Santa Clara, CA, US), fitted with a fused silica HP-INNOWax polyethylene glycol capillary column $(30 \mathrm{~m} \times 0.25 \mathrm{~mm}, 0.25$ $\mu \mathrm{m}$ inner diameter) (Agilent Technologies, Santa Clara, CA, U.S.A.), coupled with HP 5975C mass spectrometer and 7693A automatic liquid sampler injector (Agilent Technologies, Santa Clara, CA, U.S.A.). Compound identification was performed using the NIST Mass Spectral Libraries Database (rev08) and the in-house CREA-VE database. Compound content was calculated as $\mu \mathrm{g}$ IS/kg of dried grape (d.g.). 
2.7 Analysis of stilbene compounds

Sample preparation for HPLC/DAD analysis was performed using the methods suggested by Bavaresco et al. and Repetto et al. modified to meet the study's goals $[37,38]$. The skins of 20 berries were homogenized with $45 \mathrm{~mL}$ of methanol using a T25 Ultra-Turrax ${ }^{\circledR}(\mathrm{IKA} \circledast$-Werke GmbH \& Co. KG, Staufen, Germany) and kept under stirring for $20 \mathrm{~min}$ in the dark at room temperature. The extract was centrifuged, and to the supernatant of $200 \mu \mathrm{L}$ of trans-4-hydroxystilbene, $9.6 \mathrm{mg} / \mathrm{L}$ solution in methanol was added as internal standard. The solution was evaporated to dryness under vacuum at 40 ${ }^{\circ} \mathrm{C}$, and the residue was suspended in $10 \mathrm{~mL}$ of $\mathrm{HCl} 10^{-3} \mathrm{M}$ in water. After the addition of $5 \mathrm{~g}$ of $\mathrm{NaCl}$, the solution was extracted $3 \times 5 \mathrm{~mL}$ with ethyl acetate. Ethyl acetate extract was evaporated to dryness under vacuum at $40^{\circ} \mathrm{C}$ and reconstituted with $4 \mathrm{~mL}$ of methanol/aqueous $\mathrm{H}_{3} \mathrm{PO}_{4} 5 \cdot 10^{-3} \mathrm{M}$ 30:70 (v/v) solution. Finally, the sample was filtered through a $0.22 \mu \mathrm{m}$ PTFE filter and analysed by High Pressure Liquid Chromatography (HPLC). The HPLC system used was a 1220 Infinity G4290B coupled with a Gilson 170 G1315A DAD-UV detector (Agilent Technologies, Santa Clara, CA, USA) equipped with an RP C18 column (ODS Hypersil ${ }^{\circ} 200 \mathrm{~mm} \times 2.1 \mathrm{~mm}$ i.d., 5 mm, Thermo HypersilKeystone). Elution was performed using a binary solvent composed of A) methanol and B) $\mathrm{H}_{3} \mathrm{PO}_{4} 5 \cdot 10^{-3} \mathrm{M}$ in water and the following gradient program: from 25 to $30 \%$ of $\mathrm{A}$ in $30 \mathrm{~min}$, from 30 to $35 \%$ of $\mathrm{A}$ in $20 \mathrm{~min}$, from $35 \%$ to $75 \%$ of $\mathrm{A}$ in $10 \mathrm{~min}$, from $75 \%$ to $85 \%$ of $\mathrm{A}$ in 15 , from $85 \%$ to $25 \%$ of $\mathrm{A}$ in $5 \mathrm{~min}$ and isocratic for $20 \mathrm{~min}$ (flow rate 0.25 $\mathrm{mL} / \mathrm{min}$, injection volume $10 \odot \mathrm{L}$ ). trans-Piceid, trans-resveratrol, trans-piceatannol, trans$\varepsilon$-viniferin and $\delta$-viniferin were quantified by recording the chromatograms at $307 \mathrm{~nm}$, cis-piceid at $285 \mathrm{~nm}$. The UV-Vis spectra in the $200-400 \mathrm{~nm}$ range were also recorded. Standard of trans-resveratrol, piceatannol, trans-piceid and trans-4-hydroxystilbene were purchased from Sigma-Aldrich (Milan, Italy); $\delta$-viniferin was provided by CT Chrom (Marly, Switzerland). cis-Piceid was produced by photoisomerization of trans isomer; trans- $\varepsilon$-viniferin was extracted from a lignified vine cane of Gamaret following the method described by Pezet et al. [39].

Qualitative profiles of stilbenes were characterized by using an Ultra-High Performance Liquid Chromatography (UHPLC) Agilent 1290 Infinity system coupled with Agilent 1290 Infinity Autosampler (G4226A) and Agilent 6540 accurate-mass Quadrupole-Time of Flight (QTOF) Mass Spectrometer (nominal resolution 40.000) equipped with Dual Agilent Jet Stream Ionization source (Agilent Technologies, Santa Clara, CA) and the methods previously described [40-41].

2.8 Winemaking and wine tastings

The winemaking was made via micro-vinification carried out at the vinification centre of the cooperative nurseries of Rauscedo (VCR) where about 150/180 kg of dried grapes were used for each vinification obtaining about $60 \mathrm{~L}$ of vine, as previously described by Alessandrini et al. [42]. The vinification process started with the collection of withered grapes when the $30 \%$ weight loss was reached, after that the cluster were crushed and pressed to obtain the must. The must was put in a fermenter with the addition of $10 \mathrm{~g} / \mathrm{hl}$ of potassium metabisulfite, $0.3 \mathrm{~g} / \mathrm{t}$ of enzymes (Lysis first, Oenofrance $\left.{ }^{\circledR}\right), 5 \mathrm{~g} / \mathrm{hl}$ of ascorbic acid and $0.5 \mathrm{~g} / \mathrm{t}$ of tannin. Afterwards, a sample of must has been picked up and inoculated with $20 \mathrm{~g} / \mathrm{hl}$ of selected yeast (Zymaflore ${ }^{\circledR}$ FX10 and F83, Laffort ${ }^{\circledR}$ ), with the addition of $2 \mathrm{~g} / \mathrm{t}$ of Vivactiv ${ }^{\circledR}$ Premier (Oenofrance $\left.{ }^{\circledR}\right), 2 \mathrm{~g} / \mathrm{t}$ of Vivactiv ${ }^{\circledR}$ Arome (Oenofrance ${ }^{\circledR}$ ) and $2 \mathrm{~g} / \mathrm{t}$ of Philya cys (Oenofrance ${ }^{\circledR}$ ), and then remixed incorporating it in the fermenter. After $48 \mathrm{~h}$ from the inoculation, to favour malolactic fermentation, 1 $\mathrm{g} / \mathrm{hl}$ of Oenococcus oeni bacteria (Lalvin VP41®, Lallemand ${ }^{\circledR}$ ) has been added. Once a determinate alcoholic level has been reached in the must, a high-alcohol tolerant yeast at a concentration of $30 \mathrm{~g} / \mathrm{hl}$ was added (Lalvin 2226®, Lallemand( ${ }^{\circledR}$ ), also adding $15 \mathrm{~g} / \mathrm{hl}$ of 
mineral nutrients (Vivactiv ${ }^{\circledR}$ Performance, Oenofrance $\left.{ }^{\circledR}\right)$. At the end of the fermentation, a soft pressing of grapes was performed and $5 \mathrm{~g} / \mathrm{hl}$ of tannin (Tannino Perfect ${ }^{\circledR}$ ), $5 \mathrm{~g} / \mathrm{hl}$ of potassium metabisulfite, $15 \mathrm{~g} / \mathrm{hl}$ of Vivactiv ${ }^{\circledR}$ Control (Oenofrance $®$ ) and $10 \mathrm{~g} / \mathrm{hl}$ of Philya LF (Oenofrance ${ }^{\circledR}$ ) was added. Successively, the malolactic fermentation was favoured bringing the must at $21^{\circ} \mathrm{C}$ after a decanting of it 3 days later. At the end of the malolactic fermentation another decanting was performed and 2,5 $\mathrm{g} / \mathrm{hl}$ of enzyme (Lallzyme MMX ${ }^{\mathrm{TM}}$ ) was added. The temperature was reduced at $10{ }^{\circ} \mathrm{C}$ and for four weeks a batonnage was performed twice per week. At the end of the batonnage, another decanting operation was performed, and the temperature was reduced at $10{ }^{\circ} \mathrm{C}$ for two weeks. At the end of this period, the wine has been filtered with cardboard filters, stabilised with Cryokappa (Oenofrance ${ }^{\circledR}$ ), and brought at $-5{ }^{\circ} \mathrm{C}$ for 3 weeks. After that, the wine was filtered again with a, firstly, $1 \mu \mathrm{m}$, and secondly, $0.45 \mu \mathrm{m}$, candle filter and bottled.

The tasting analysis was carried out in Conegliano (TV) at CREA-VE by a test panel made up of 10 expert judges plus a panel leader. For the quantitative evaluation of the intensity of attributes (olfactory, gustatory-tactile and retro-olfactory), Quantitative Descriptive Analysis was used [43] with the help of a question sheet providing discrete scale responses with intervals from 1 to 9 . For each of the three attributes, the relative differences between wines were analysed and confirmed, submitting the judgements to statistical analysis using the ANOVA method (F-test p-values $<0.0001 ;[44]$ ). The 2016 and 2017 wines were tasted one year following vinification; the wines were stored in stainless steel tanks in a temperature-conditioned cellar at $12-14{ }^{\circ} \mathrm{C}$.

\subsection{Statistical analysis}

One-way analysis of variance was performed using " $R$ " freeware. Statistical analyse to determine significant differences between treatment means was carried out using the Student-Newman-Keuls test $(\mathrm{p} \leq 0.05)$.

\section{Results}

3.1 Temperature - humidity mean and kinetics of withering (WL) in two years of study, in $\mathrm{C}$ and $\mathrm{NC}$ environment

In order to describe the kinetics of withering, namely the velocity of WL and sugar concentration, using climate data collected inside and outside the withering chambers, mean temperature and mean humidity per day were measured throughout the two test years. The weather conditions of the test locality (Negrar) were also taken into account to understand the difference between treatments inside and outside the chambers. In 2016 (Fig. 1), the C chamber's average temperature values were higher than in the NC one. On average, the temperatures in the chamber conducted in $\mathrm{NC}$ were closest to the outside ones. The relative humidity was comparable in the two conditions $\mathrm{C}$ and NC though C presented a slightly lower level than NC, mainly at the beginning of the process when the WL from the berries was higher, while the external treatment followed the normal trend of the daily weather conditions.

As for 2017 (Fig. 2), the average temperature was again higher in C and lower in NC, and in this case, NC was also closest to the external one. As air humidity was controlled in the $\mathrm{C}$ withering chamber, this parameter was lower in $\mathrm{C}$ conditions and higher in NC conditions, while the external humidity level was lower or in the middle between that of the NC and C conditions and presented more abrupt variability. 


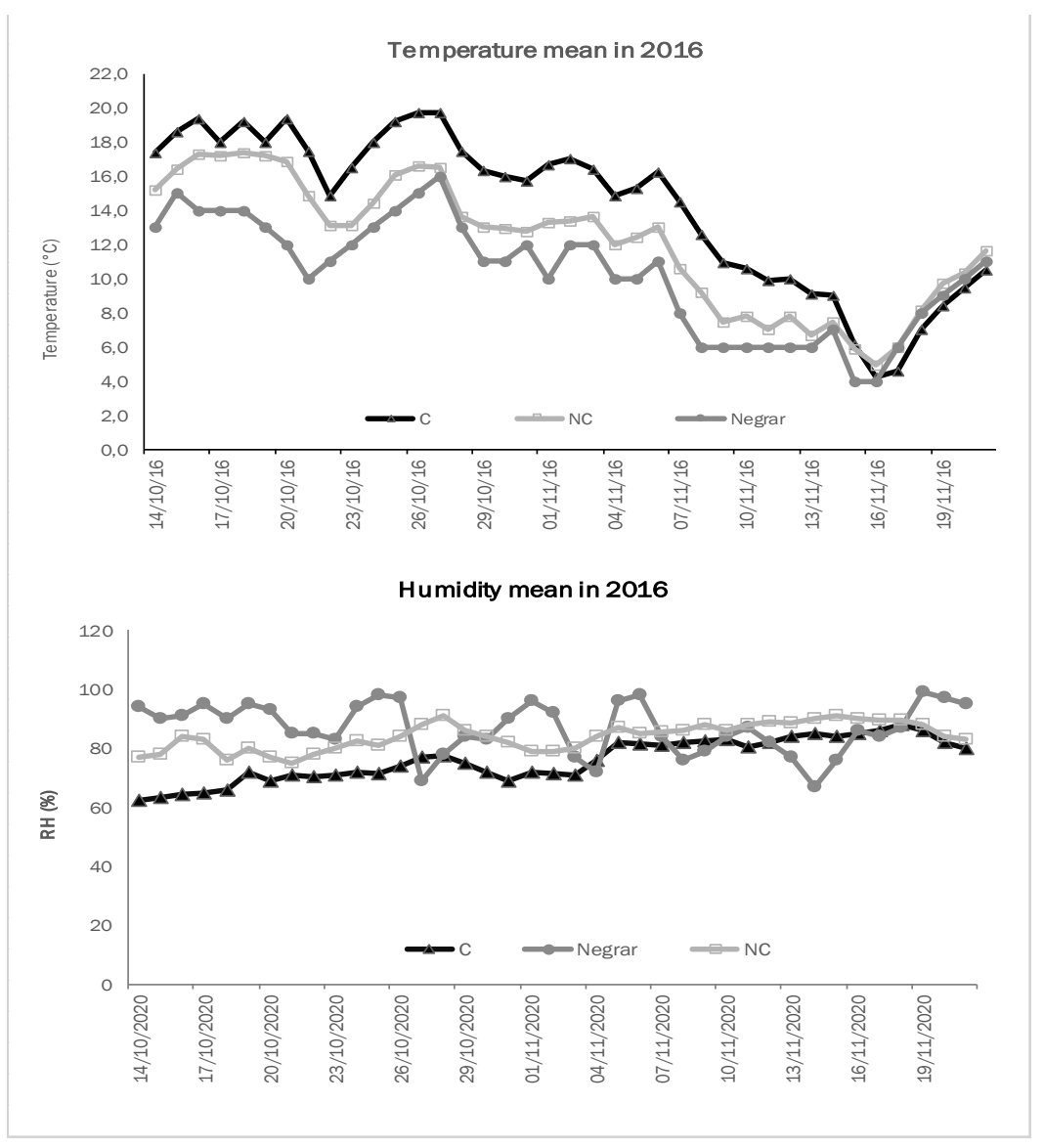

Figure 1 Daily mean air temperature and humidity in controlled (C) and not-controlled (NC) chambers and outside environment (Negrar) in 2016 

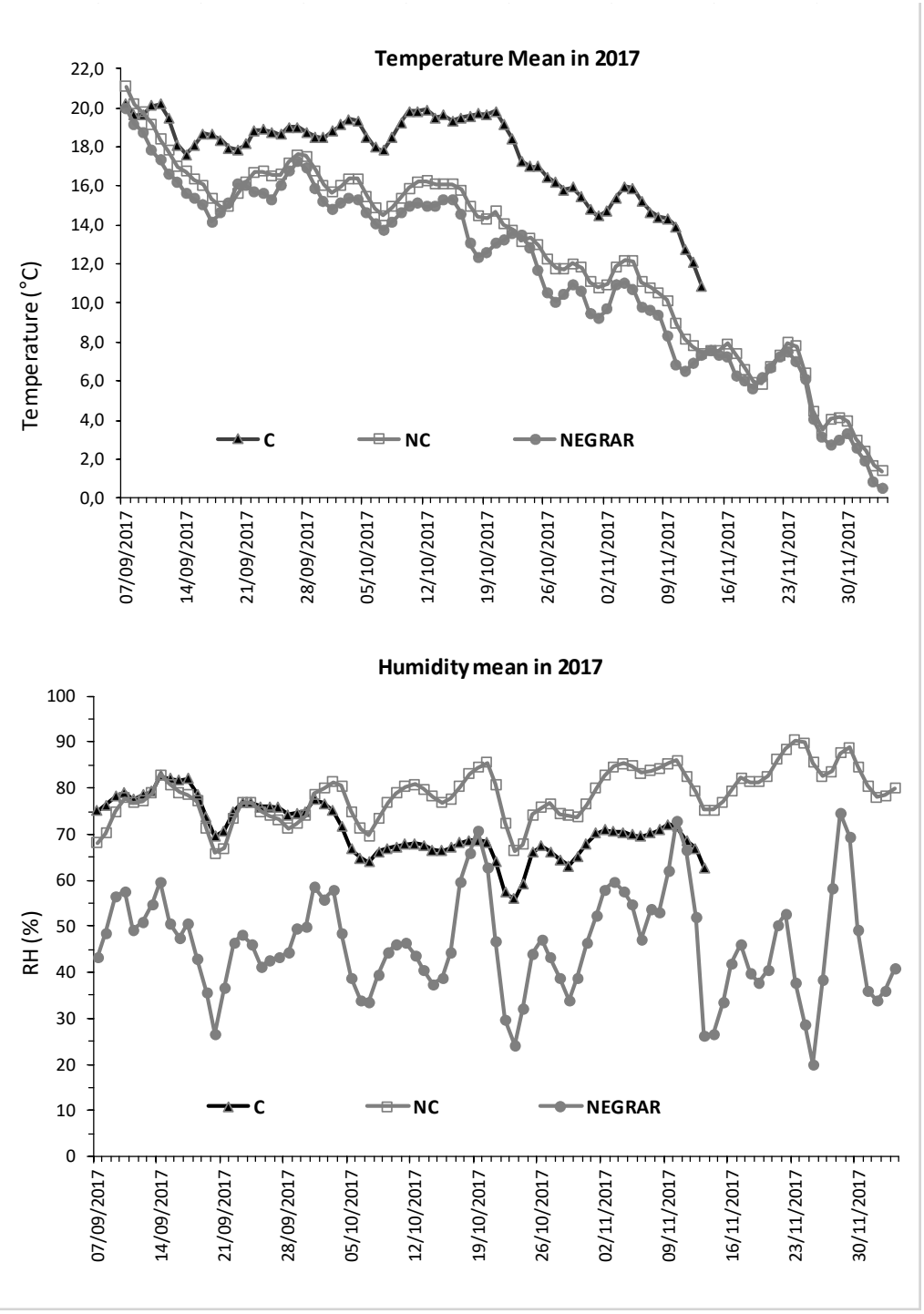

Figure 2 Daily mean air temperature and humidity in controlled (C) and not-controlled (NC) chambers and outside environment (Negrar) in 2017

As previously reported, $\mathrm{T}$ and $\mathrm{H}$ are fundamental for the kinetics of WL. Hence, measurements of the kinetics of withering were taken and are indicated as a percentage of weight loss during the period of withering, starting from time 0 (grape set - aside) to 30\% WL (Fig. 3). 2016 evidenced a faster withering in C than NC throughout the entire period, and $-30 \%$ WL was reached \pm 17 days earlier in C than in NC. In 2017 there were no significant differences between treatments during the first period of withering $(-20 \%$ WL), but at the end, $-30 \%$ WL was once again reached earlier in C ( \pm 14 days) than in NC. 

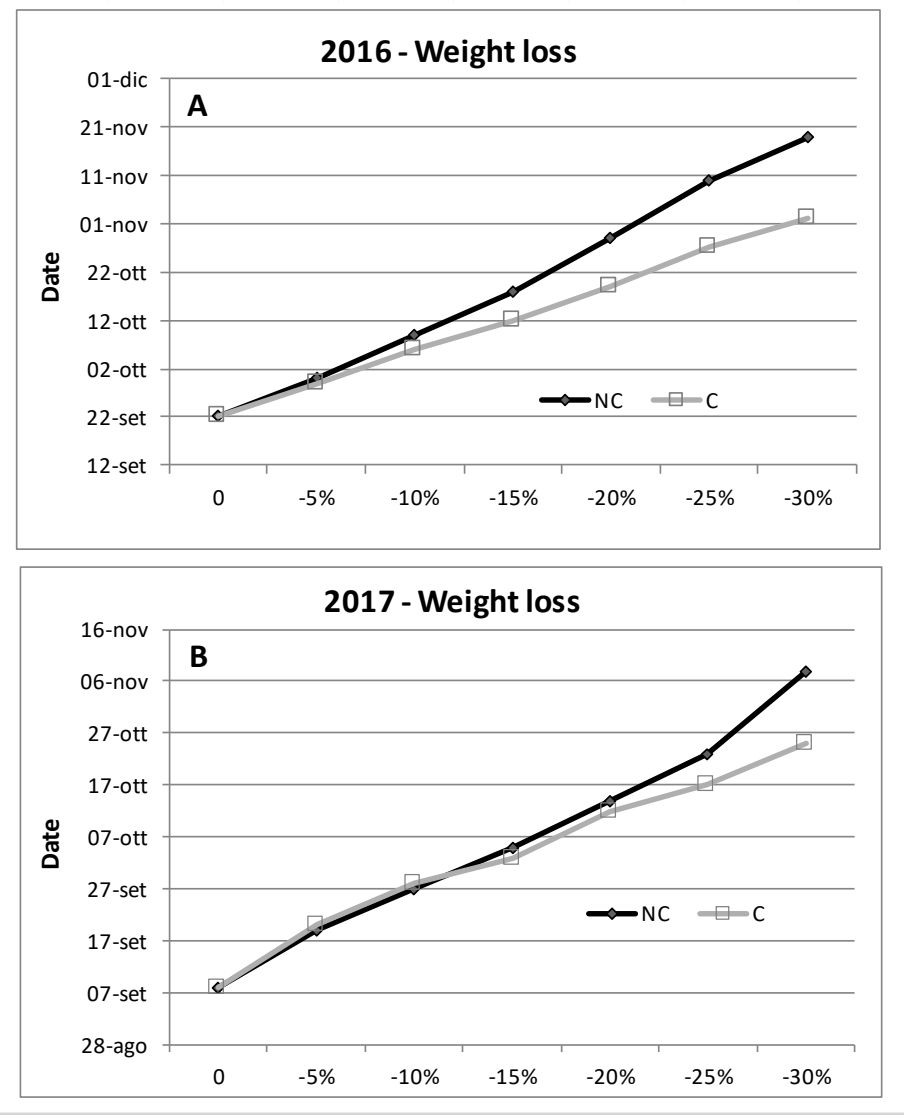

Figure 3 Kinetics of withering: WL in 2016 (A) and 2017 (B)

\subsection{Sugar accumulation trend}

During withering, generally, a concentration of sugars occurs due to the berry water loss. The two test years (Fig. 4) evidenced a gradual and constant accumulation of sugars with a similar trend between C and NC. In 2016 the grape set - aside started on 17 September; in this year, NC grapes showed a slower accumulation of sugars than C, but at the end $(-30 \% \mathrm{WL})$, there were no differences in sugar concentration between treatments. In 2017 the grape set - aside started on 6 September, and the trend of sugar enrichment was similar. In this year, in NC there were more degrees than in $\mathrm{C}$, during all the periods. The berry sugar content was 30.2 and 30.8 Brix degree in 2016, 27.0 and 28.6 in 2017, for the C and NC conditions, respectively. At -30\% WL, the NC treatment showed a higher degree than C, explicitly highlighted in 2017. In 2016 the outside RH was higher than in 2017; as a consequence, $\mathrm{C}$ conditions showed markedly lower room $\mathrm{RH}$ compared to $\mathrm{NC}$, which can explain the fact that $\mathrm{C}$ sugar accumulation was faster in $\mathrm{C}$ conditions. In 2017 the external weather conditions were different compared to those in 2016. Indeed, the air RH was much lower, and it was easier to control the room RH even in the NC treatment (see the similar level in RH between C and Nc reported in fig. 2 ), which can explain the similar trend in sugar accumulation. The last two considerations refer to the final sugar enrichment, which tends to be higher in NC conditions, and to the fact that the first stage of sugar enrichment tends to be more active in $C$ conditions. 


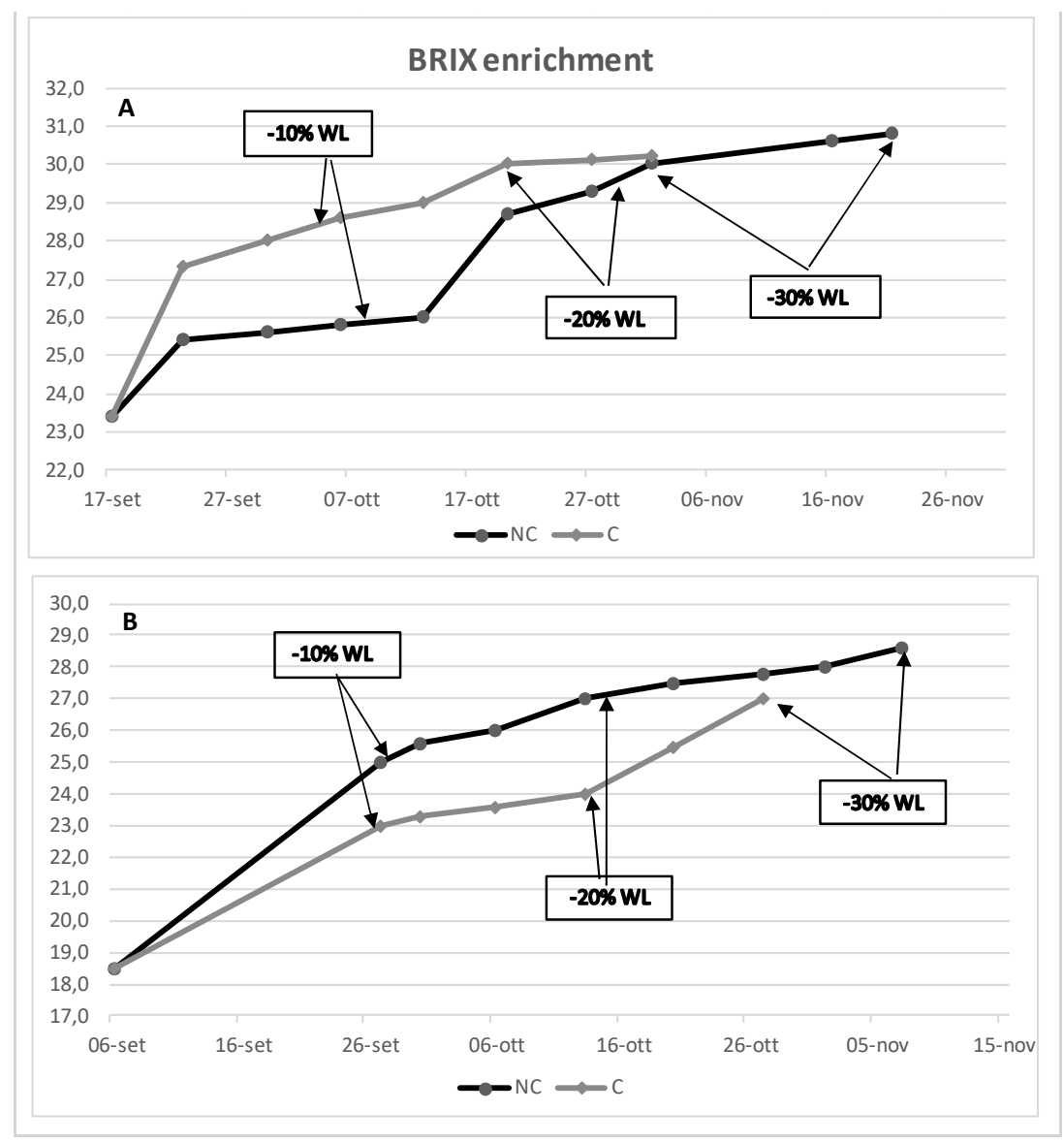

Figure 4 Brix degree enrichment in 2016 (A) and 2017 (B). Arrows means different WL values

3.3 Accumulation of acid trend and content in specific acid compounds

Because of water evaporation and WL, acids tend to be accumulated during withering. The analysis of the two tested years reported an almost specular behaviour in terms of total acidity (Fig. 5). In 2016 the trend was similar in both treatments, with only a minor decrease in NC at the beginning of the process, but the acidity in NC was slightly above $\mathrm{C}$ with no significant differences during the final stage of the process. The trend was confirmed in 2017, where acidity levels were very close during the whole period of the drying process, except for the last stage when the NC environment displayed higher acidy with a final significant difference. Moreover, regarding the components of acidity (Fig. 6), in 2016, the level of tartaric acid in NC remained the same, but during the final stage $(-30 \% \mathrm{WL})$, it increased, while in $\mathrm{C}$, there were no significant differences throughout the WL process. As for malic acid, there were no differences between $\mathrm{C}$ and NC at the different stages of WL. In 2017, at the different stages of WL, tartaric acid was consistently higher in NC than in C. The highest content was found at $-30 \% \mathrm{WL}$ for NC. Regarding malic acid, the concentration was higher in the second part of the drying process, with no difference between the two treatments. 


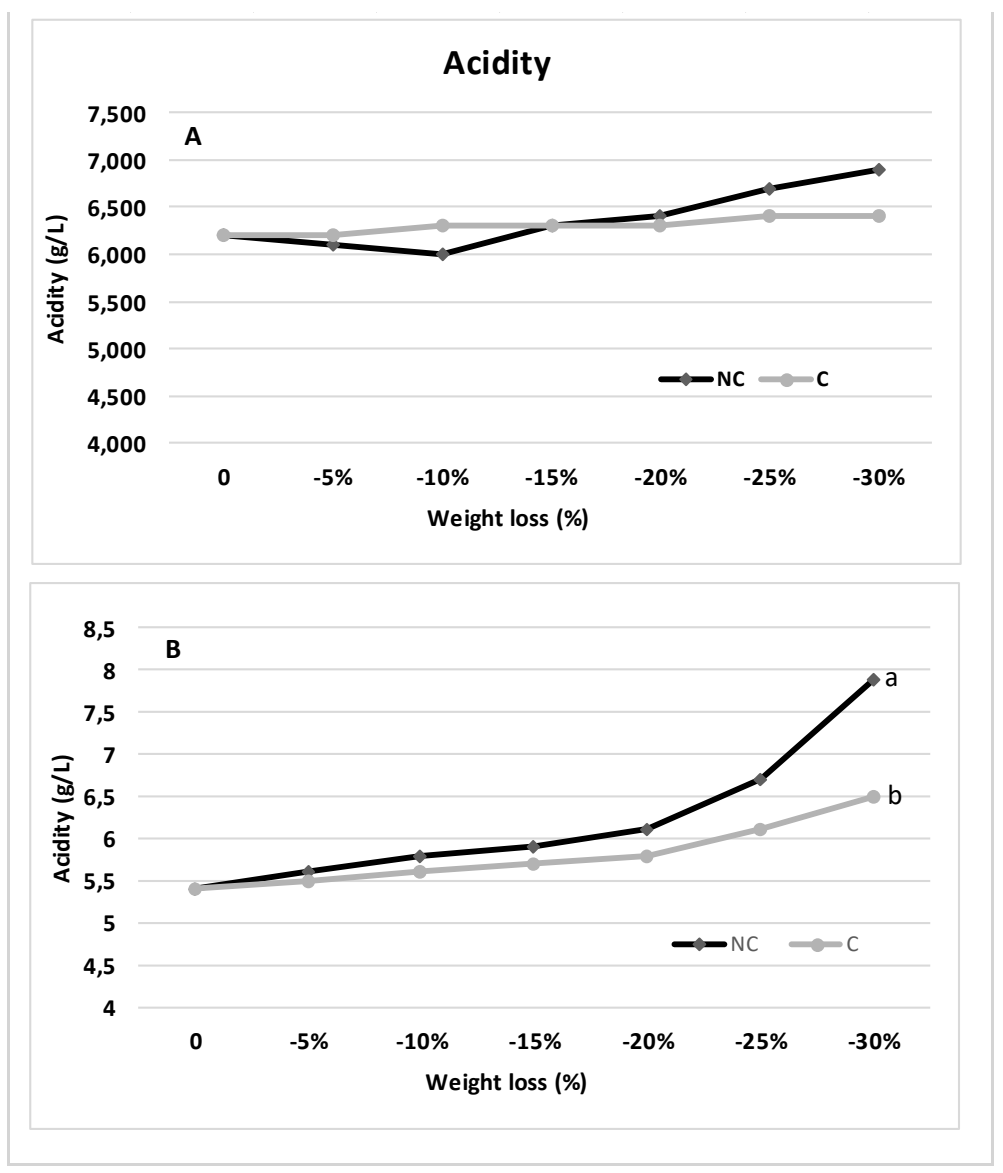

Figure 5 Total acidity in 2016 (A) and 2017 (B) at harvest date and different WL stages. Values indicated with different letters were significantly different $(p<0.05)$ 


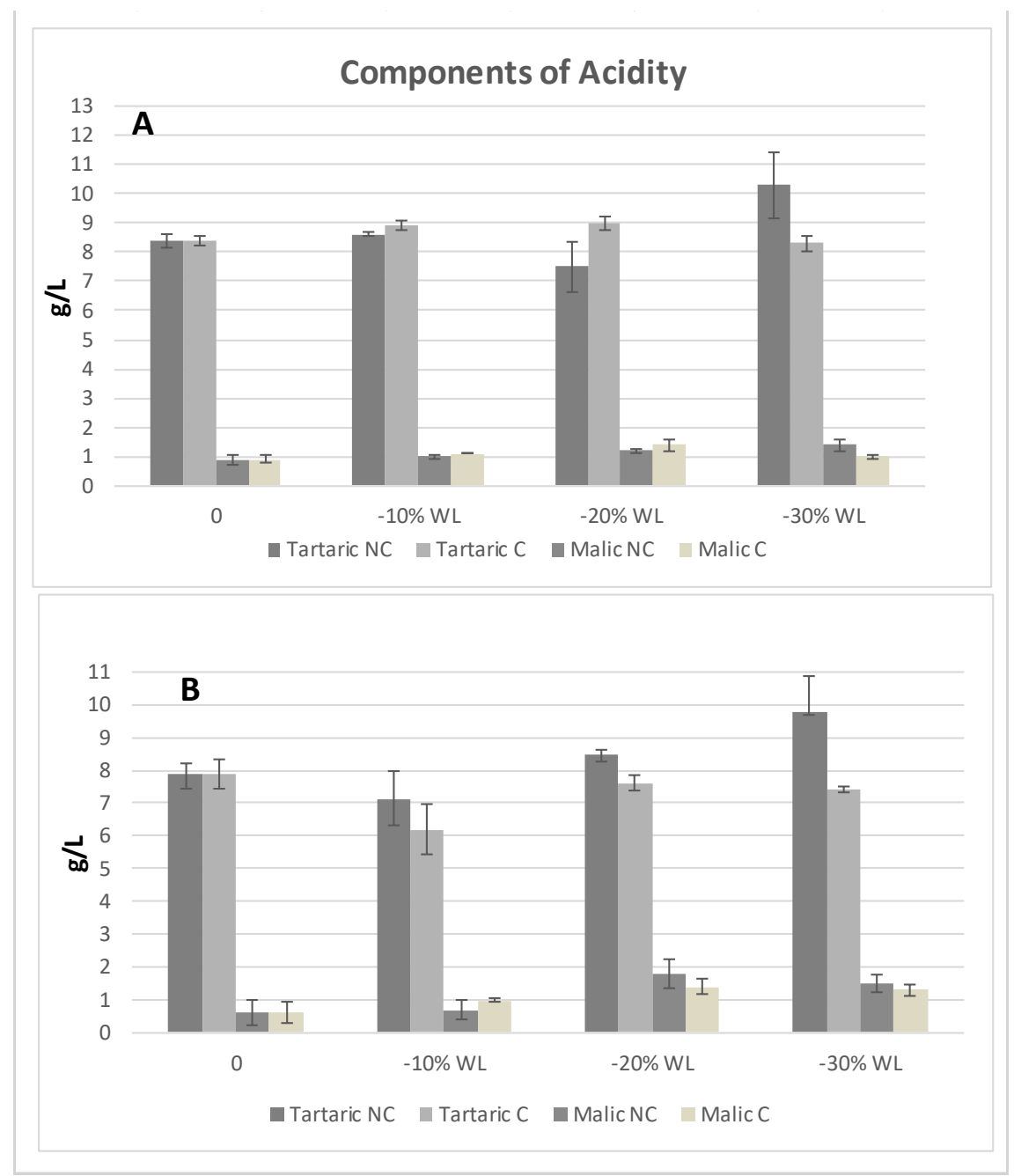

Figure 6 Components of total acidity in 2016 (A) and 2017 (B). Vertical bars indicate Standard Deviation. No statistical differences were found

\subsection{Colour substances accumulation trend}

Different climate conditions inside the withering chambers may affect the berry colour compounds. At the end of the process, the content in total polyphenols consistently predominated in NC in the two tested years of study (Fig 7 and 8). In both years, total polyphenols were higher in NC at $-30 \%$ WL $(2586 \mathrm{mg} / \mathrm{kg}$ berries t.q. in C vs 2933 in NC in 2016, 1550 in C vs 2.000 in NC in 2017). Specifically, in 2016, the accumulation trend was similar in $\mathrm{C}$ and $\mathrm{NC}$, furthermore, the differences between the two treatments were significant only at $-30 \%$ WL $(p \leq 0.05)$. In 2017 , the trend was again similar in C and NC but, the differences became highly significant starting from the $10 \% \mathrm{WL}$ stage. As for anthocyanins concentration, in 2016, there were no differences during the initial stage ($10 \% \mathrm{WL}$ ), whilst at the end of the drying period, NC grapes had $11 \%$ more anthocyanins than C grapes (614 mg/kg berries t.q. and 549 for C and NC, respectively). In the second year (2017), there was a considerably higher and more meaningful content in NC than $\mathrm{C}$ at every stage of WL (at -30\% WL: $242 \mathrm{mg} / \mathrm{kg}$ berries t.q. in C vs $380 \mathrm{mg} / \mathrm{kg}$ in NC, + $36 \%)$. 
The anthocyanin profile of Corvina is constituted by malvidin, peonidin, petunidin, delphinidin, and cyanidin monoglucosides and their acyl derivatives where malvidin-3$\mathrm{O}$-monoglucoside is the main compound. Findings did not show relevant differences between the two processes in terms of changes regarding single anthocyanins (data not showed).

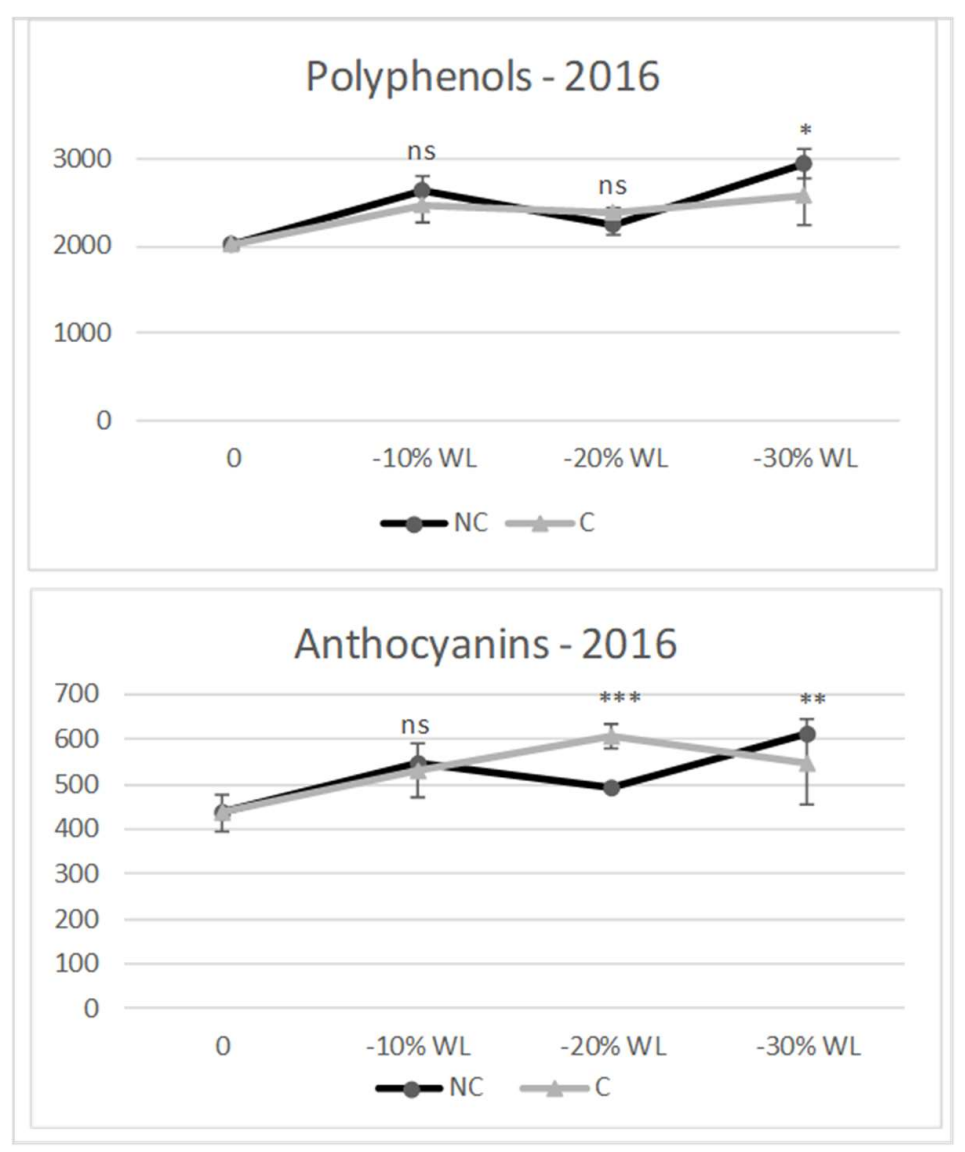

Figure 7 Content in polyphenols and anthocyanins in 2016. Data are the mean of three berry samples. ***;*** indicate a significant difference $(p \leq 0.05,0.01,0.001)$ between $C$ and NC treatment. Vertical bars indicate standard deviation 


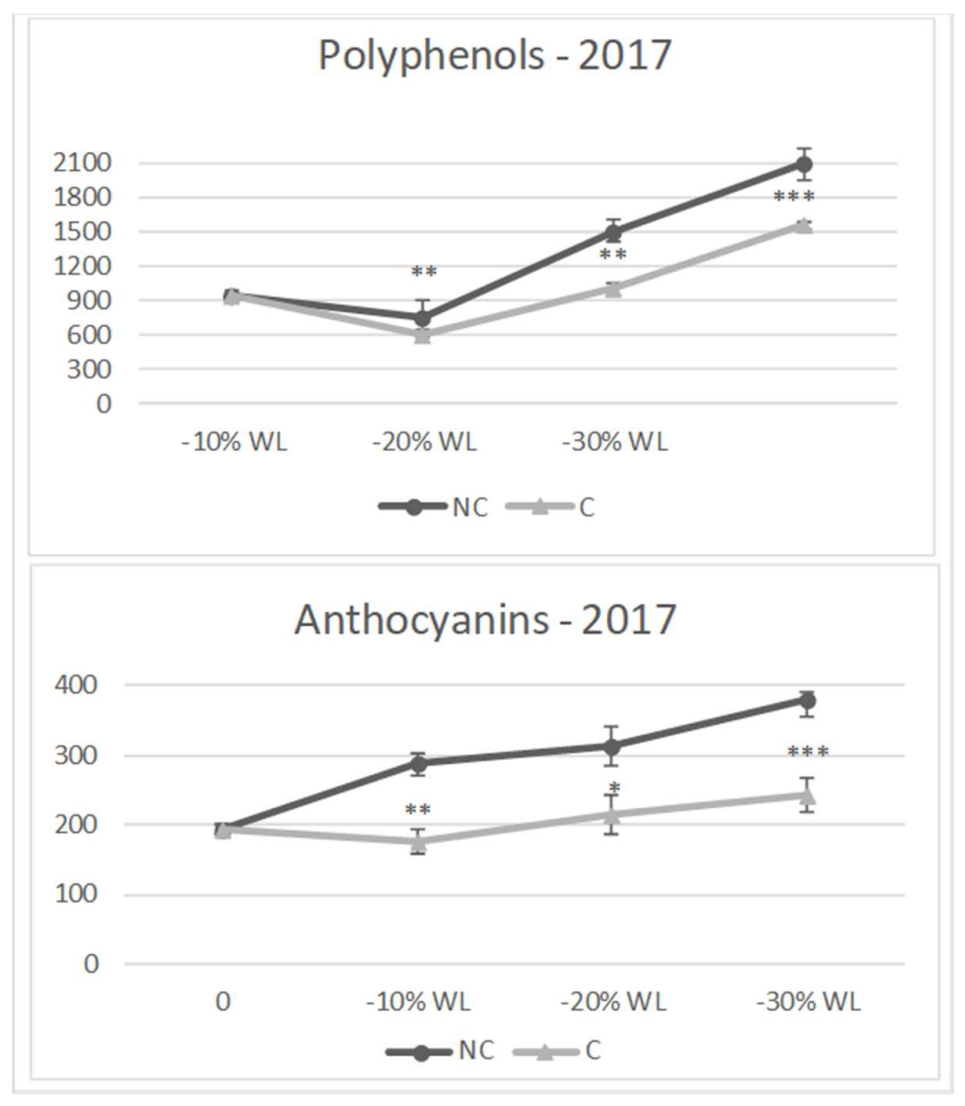

Figure 8 Content in polyphenols and anthocyanins in 2017. ${ }^{* * *} ;{ }^{* * *}$ indicate a significant difference ( $p \leq 0.05,0.01,0.001)$ between $C$ and NC treatment. Vertical bars indicate standard deviation

\subsection{Synthesis of stilbenes}

Withering induces specific chemical changes in the berry, and most of them involve secondary metabolites. In particular, the biosynthesis of stilbenes is promoted by abiotic stress - e.g., cell dehydration - and these compounds determine the nutraceutical properties of the grapes and wines. The profile of stilbenes in Corvina grape during withering was characterized by liquid chromatography/quadrupole-time of flight mass spectrometry (UHPLC/QTOF), and the 19 compounds reported in supplemental material Table S1 were identified. They included trans-resveratrol, cis and trans-piceid, piceatannol, $E$ and Z-astringin, pallidol, four viniferins ( $E$ - and Z- $Z$-viniferin, Z- $\omega$ viniferin, $\delta$-viniferin) and another resveratrol dimer, caraphenol, pallidol-glucoside, ๑viniferin, two resveratrol trimers ( $E$ - and Z-miyabenol $C$ ) and two resveratrol tetramers. HPLC/DAD quantification of the compounds showing the higher signals, where the standards were available, was performed. Data in Figure 9 show an accumulation of trans-resveratrol and total stilbenes in the grapes during both processes carried out in two years.

In 2016, a constant increase in trans-resveratrol and total stilbenes were observed throughout both withering processes. In particular, until the $-20 \%$ WL stage, stilbenes were higher in the NC samples. In the last stage (between -20-30\% WL), the level of stilbenes in NC samples remained constant, while in the C samples, it continued to 
increase, reaching the other process. In the latter year, the trend was different: at $-10 \%$ $\mathrm{WL}$, both processes induced a low stilbene increase, and the levels remained similar until the $-20 \%$ WL stage. A sudden increase in the synthesis of stilbenes was observed during the last stage in both processes, as well as higher accumulation in the $\mathrm{C}$ samples.

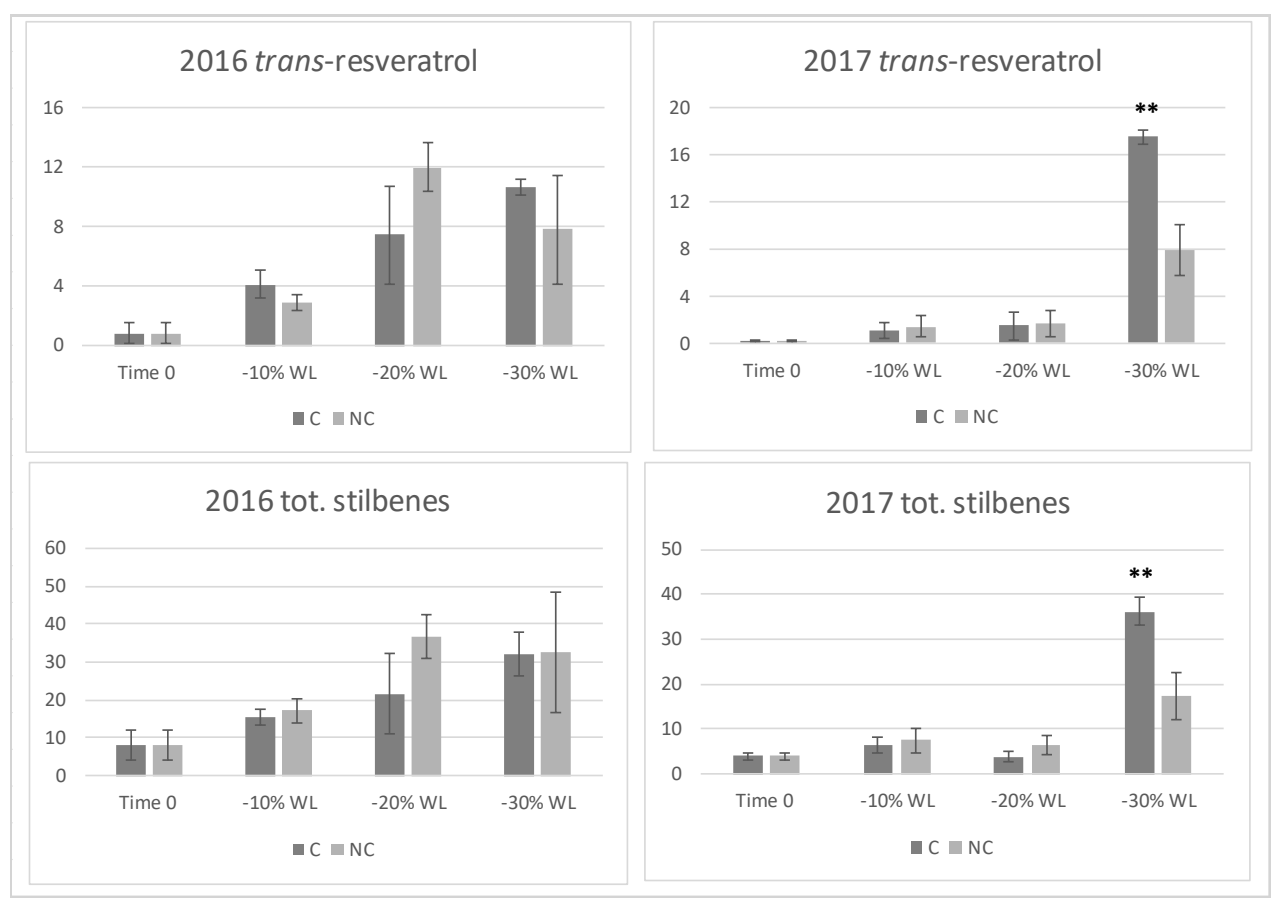

Figure 9. Levels of trans-resveratrol and total stilbenes calculated as mg transresveratrol $/ \mathrm{kg}$ d.g. (dried grape) during two withering processes carried out in the two years. C, dehydration in RH and WS controlled warehouse; NC, dehydration carried out in the not-controlled environment. ${ }^{* *}$ indicate a significant difference $\mathrm{p} \leq 0.01$ between two processes. Vertical bars show the standard deviation of 3 data.

3.6 Accumulation of glycoside aroma precursors in berry

Glycoside aroma precursors identified in Corvina grape belong to different chemical classes of compounds, and the sums of their contents in the grape berry expressed as $\mu \mathrm{g}$ IS/kg d.g., are reported in Table 1. Tables S2 and S3 show the contents of the single compounds in the two years of study.

Glycoside aliphatic alcohols identified were 1-butanol, 3-methyl-1-butanol, 3-methyl-2butene-1-ol, 3-methyl-3-butene-1-ol, 1-hexanol, E- and Z-3-hexen-1-ol, 2-butoxyethanol, and 2-hexenol. In 2016, C samples had higher levels of total aliphatic alcohols, but a significant difference $(\mathrm{p} \leq 0.05)$ between $\mathrm{C}$ and $\mathrm{NC}$ samples was found only at the highest content at $-20 \%$ WL stage. In 2017, the total content was higher in NC with a significant difference at $-20 \%$ and $-30 \% \mathrm{WL}$, the highest aliphatic alcohols content was reached at $30 \%$ WL in both C and NC.

Glycosides of the $\mathrm{C}_{6}$-aldehydes hexanal and 2-hexenal, were identified, these two compounds confer to the wines herbaceous/grassy notes. Their content was higher in 
NC in both years but, a significant difference among $C$ and NC thesis, was found at $-10 \%$ and $-30 \%$ WL in 2016 and at -20/-30 WL in 2017. In both years, the highest concentration was achieved at $-20 \% \mathrm{WL}$.

Fourteen glycoside monoterpenes were identified in Corvina grape which include cisand trans-furanlinalool oxide, trans-pyranlinalool oxide, linalool, $\alpha$-terpineol, nerol, geraniol, diendiol I, 8-hydroxylinalool cis and trans, hydroxygeraniol, 2-exo-2hydroxycineol, 7-hydroxy- $\alpha$-terpineol and geranic acid. The highest levels were found for geraniol and 7-hydroxy- $\alpha$-terpineol. In general, the aglycones are characterized by low sensory thresholds and confer floral or citrus notes to the wines. In 2016, monoterpene total content was higher in $\mathrm{C}$ at all withering stages, a significant difference among C and NC was found at $-10 \%$ and $-20 \%$ WL. As expected, water loss increased the monoterpene concentration in the berry and the highest content was found thereabout at $-30 \%$ WL in both C and NC, but no statistical difference among the two processes was found. Indeed, in 2017 the content was higher in NC at all withering stages and significant difference between two processes was found at $-20 \%$ and $-30 \%$ WL. In general, the highest concentration in the berry were reached in the last withering stages, showing that the process does not promote degradation processes of these glycoside precursors.

$\mathrm{C}_{13}-$ Norisoprenoids are correlated to floral/spicy notes developed in red wines specially during aging. Glycoside norisoprenoids identified in Corvina grape are 3-hydroxy- $\beta$ damascenone, 3-oxo- $\alpha$-ionol, 3,9-dihydroxy-megastigma-5-ene, 3-hydroxy-7,8-dihydro$\alpha$-ionol and vomifoliol. Potentially, they are precursors of volatile compounds which contribute by conferring positive notes to the aroma of wines, such as $\beta$-damascone (fruity note), $\beta$-damascenone and 3-oxo- $\alpha$-ionone (floral, tobacco). In 2016, total content of norisoprenoids at $-10 \%$ WL was higher in C, instead at $-20 \%$ and $-30 \%$ WL the two processes showed similar levels. In 2017, the content was higher in NC samples at all withering stages with significant difference between the processes at $-20 \%$ and $-30 \%$ WL. In this year, the highest concentration of norisoprenoids was found at $-30 \% \mathrm{WL}$ in $\mathrm{NC}$, instead in C at $-20 \%$ WL.

Glycoside precursors of sixteen compounds belonging to the chemical class of benzenoid derivatives were identified: benzaldehyde (almond note), acetophenone, methyl salicylate, guaiacol, benzyl alcohol, ß-phenylethanol (rose), eugenol (clove), 4vinylguaiacol, 4-vinylphenol, syringol, vanillin (vanilla), methyl vanillate, acetovanillone, 4-hydroxybenzeneethanol, vanillic and homovanillic alcohols. In 2016, their total content during the entire process was higher in NC, and a significant difference between the two processes was found at $-30 \% \mathrm{WL}$. The highest concentration was reached at $-30 \%$ WL in NC and at $-20 \%$ WL in C samples. The second year of the study confirmed the higher contents in NC during withering, with a significant difference at $-20 \%$ and $-30 \%$ WL. In both processes, the highest accumulation of benzenoids was reached at $-30 \% \mathrm{WL}$.

Moreover, regarding the total content of aromatic compounds at every stage, in 2016, at $10 \%$ and $-20 \%$ WL the content was almost the same in both C and NC, while, at $-30 \%$ $\mathrm{WL}$, the content was higher in NC than in C, with a statistical difference between treatments. In 2017 there were more aromatic substances at every stage in NC than in C. Furthermore, at -20 and $-30 \%$ WL, statistical differences were found between treatments, with the already reported higher content in NC. 


\begin{tabular}{|c|c|c|c|c|c|c|c|}
\hline \multirow[b]{2}{*}{2016} & \multirow[t]{2}{*}{ T0 } & \multicolumn{2}{|c|}{$-10 \% \mathrm{WL}$} & \multicolumn{2}{|c|}{$\begin{array}{l}-20 \% \text { WL } \\
(\mu \mathrm{g} / \mathrm{Kg} \text { d.g. })\end{array}$} & \multicolumn{2}{|c|}{$-30 \% \mathrm{WL}$} \\
\hline & & $\mathrm{C}$ & $\mathrm{NC}$ & $\mathrm{C}$ & $\mathrm{NC}$ & $\mathrm{C}$ & $\mathrm{NC}$ \\
\hline aliphatic alcohols & 299 & 444 & 335 & $774^{* *}$ & 570 & 575 & 535 \\
\hline $\mathrm{C}_{6}$-aldehydes & 27 & 43 & $55^{*}$ & 41 & 46 & 21 & $35^{*}$ \\
\hline monoterpenes & 553 & $805^{*}$ & 692 & 862 & 877 & 857 & 813 \\
\hline $\mathrm{C}_{13-\text {-norisoprenoids }}$ & 785 & $1103^{*}$ & 914 & 1149 & 1177 & 1126 & 1144 \\
\hline benzenoids & 2401 & 4637 & 4728 & 5286 & 5472 & 4611 & $5805^{* *}$ \\
\hline Total & 4065 & 7033 & 6724 & 8112 & 8142 & 7190 & $8332^{* *}$ \\
\hline \multicolumn{8}{|l|}{2017} \\
\hline aliphatic alcohols & 485 & 538 & 460 & 456 & $552^{*}$ & 641 & $820^{*}$ \\
\hline $\mathrm{C}_{6}$-aldehydes & 58 & 55 & 70 & 120 & $138^{*}$ & 65 & $104^{* *}$ \\
\hline monoterpenes & 738 & 625 & 829 & 640 & $912^{* *}$ & 698 & $895^{*}$ \\
\hline $\mathrm{C}_{13-\text {-norisoprenoids }}$ & 1074 & 961 & $1462^{*}$ & 1485 & $1968^{* *}$ & 1164 & $2702^{* *}$ \\
\hline benzenoids & 3257 & 3258 & 3696 & 4430 & $6156^{* *}$ & 5937 & $8698^{* * *}$ \\
\hline Total & 5612 & 5437 & 6517 & 7131 & $9726^{* *}$ & 7865 & $00^{* * *}$ \\
\hline
\end{tabular}

Table 1. Glycoside aroma precursors in Corvina grape during withering. C, in-chamber dehydration under controlled conditions of relative humidity $(\mathrm{RH})$ and wind speed (WS); NC, dehydration carried out in not-controlled environment. Contents are expressed as $\mu \mathrm{g} 1$-heptanol (IS) $/ \mathrm{kg}$ d.g. (dried grape). ${ }^{* * *}, * * *$ : significant difference between the $\mathrm{C}$ and NC process ( $\mathrm{p} \leq 0.05,0.01$, and 0.001 , respectively). Contents of singular compounds in the two years of study are reported in Tables S2 and S3 supplemental material.

\subsection{Sensory analysis of the resulting wines}

Results of the tastings carried out in 2016 and 2017 are reported in Figure 10. The 2016 vintage showed a great difference between the two wines. NC generally resulted richer and more interesting regarding the olfactory scents, with low herbaceous notes and higher scores for smoothness. In the mouth, the NC wine was smoother and better appreciated in terms of finesse, taste balance and full body. The $\mathrm{C}$ wine resulted achieving less score compared to NC, which displayed more character (see full-bodied, structure) and elegance (see finesse and olfactory quality less herbaceous)

As for the 2017 vintage, the NC wines confirmed the higher pleasantness with a peak in ripe fruit combined with spicy notes. Overall, the NC wine was more harmonious with good scores in terms of taste balance and finesse. 


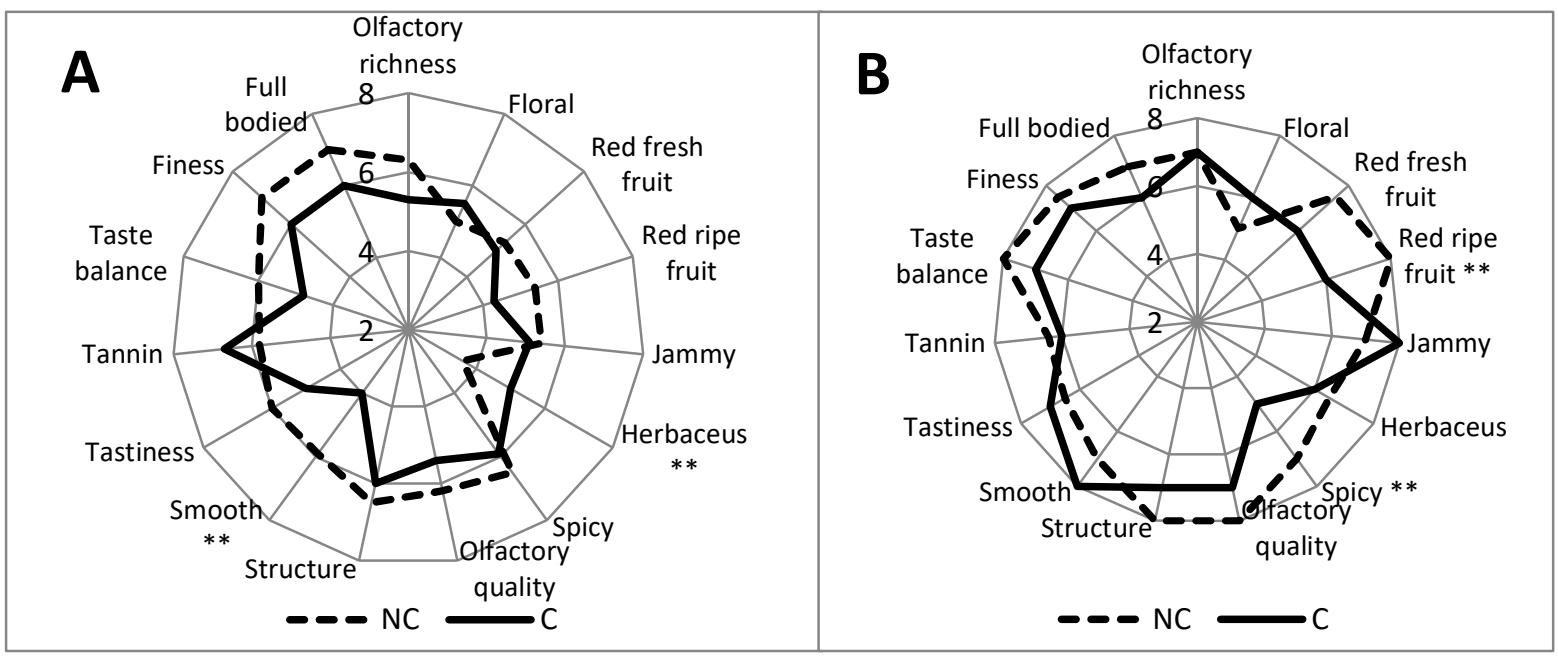

Figure 10 Results of tasting for wines in 2016 (A) and 2017 (B) years. * **; *** indicate a significant difference $(\mathrm{p} \leq 0.05,0.01,0.001)$ between $\mathrm{C}$ and $\mathrm{NC}$ treatment.

\section{Discussion}

Post-harvest dehydration has a significant impact on berry physiology and metabolism, directly influencing physical, metabolic and metabolomics aspects. For the production of Amarone wine - obtained mainly from the Corvina variety - the grapes are harvested and stored in dehydration chambers and then vinified. This specific process, which is employed to obtain reinforced wines rich in alcohol, anthocyanins, flavour and structure, seems particularly suitable for the Corvina variety - characterized by thick skin with compact layers that slow down the dehydration process. Lower water stress plays an important role in terms of transcriptional modulation and metabolic change $[32,44]$. The process could be carried out either in dehydration chambers under natural environmental conditions, where the airflow from the outside towards the inside is promoted through careful window management, or in chambers with controlled environmental parameters ( $\mathrm{RH}$ and wind speed). As known, dehydration of berries post-harvest impacts the compound content of the berries and wine [2,7]. In this context, a different level of dehydration-chamber control, in terms of environmental conditions, is important for WL kinetics (Fig. 3), also because this process can strongly influence the composition of the berries, as described previously (Fig. 4); these components, of course, also influence the wine profile. (Fig. 10). For this purpose, we investigated the composition of the berries before and after withering in two tested years and two different environmental conditions.

The microclimatic analysis of the chambers used for tests confirmed a different air thermal and humid regime in the two situations: lower temperatures and higher humidity in NC, higher temperatures, and lower humidity in $\mathrm{C}$, for both tested years (Fig. 1 and Fig. 2). Furthermore, NC temperature was consistently closest to the external thermal conditions simulating the external regime. Thus, the NC must be conducted skilfully as the only action possible to counter the onset of Botrytis (favoured by high humidity) and regulate the dehydration kinetics is by careful management of the internal airflow, performed by opening and closing the windows of the dehydration chambers as needed. $\mathrm{T}$ and $\mathrm{RH}$ are directly related to the kinetics of withering; indeed, 
they entail the transference of energy and water from the berries into the environment. Concerning this parameter, in both years, the trend of weight loss was faster in $\mathrm{C}$ conditions than in NC, and consequently, $-30 \% \mathrm{WL}$ was reached earlier in C (2 weeks). This could have resulted because the highest $\mathrm{T}$ and lowest $\mathrm{RH}$ for $\mathrm{C}$ led to a faster transference of energy and water from the berries into the environment due to the higher value of vapour pressure deficit (VPD), resulting in a faster WL.

Moreover, higher ventilation in $\mathrm{C}$ can facilitate water loss from berries due to removing the boundary layer, [46] reducing the $\mathrm{RH}$ around the berry and accelerating the WL. It is also interesting to note that in 2017 the WL at the beginning of the drying process was very close between $\mathrm{C}$ and NC. Such evidence can be attributable to the similar thermal and humidity conditions in the two dehydration chambers and linked to the external low air humidity.

Regarding the berry chemical composition (Fig. 4), the sugar accumulation trend during the period of withering was different between tested years: in 2016, there were no significant differences between treatments, and there was a high enrichment in the first week following harvest, while in 2017, there was a slightly higher degree in NC than in $\mathrm{C}$ conditions, which can be related to the low $\mathrm{RH}$ of the and, consequently, a better condition in NC than in C (lower T and similar RH). Observing the rate of sugar increase between the two postharvest maintenance of the grapes, even if the trend is similar as well as the final values, throughout the drying period, the rate of increase in sugar cannot be explained only by the rate of WL, and indeed, for the same WL, there were different values in sugar enrichment between treatments. An explanation could be found in the consequences that different combinations of the climatic elements $(T, R H$, Wind) can produce during the dehydration process in terms of acceleration in sugar release from the cell wall, [47] mainly galactose [48].

Measurements taken included acidity (Fig. 5 and Fig. 6) and its component in tartaric and malic acid. The accumulation trend was similar between treatments in the period of withering, with a predominance of total acidity in NC, especially in 2017. More in detail, tartaric acid was more stable and tended to remain unaltered and even accumulate during the withering process at the different stages of WL, evidencing a greater concentration in NC conditions in almost every stage of weight loss. Malic acid performed differently, showing a smaller conservation capability due to its rapid consumption during the initial stage of grape dehydration [49]; its enrichment throughout the drying period was almost immeasurable or very minimum. These results suggested that the most significant accumulation of sugars and acidity could occur at -30 $\%$ WL. Considering acidity, the different content at $-30 \%$ WL was entirely in favour of the NC conditions, mostly due to tartaric acid concentration. The faster withering in C likely led to less accumulation of these compounds due to the respiration of tartaric and malic acids as acidity strongly depends on water and temperature stress [33].

Many factors determine the accumulation of colouring substances: the level of ripeness of the grapes [50], thermal stress [51], light [52,53] and water [54]. However, the drying process affects the anthocyanins enrichment by concentration and neoformation (Fig. 7 and Fig. 8) [26,55]. Moreover, the drying process damages the cellular structure of the grape skin, which facilitates the extraction of anthocyanins [56-57]. We then performed a focused analysis of the secondary metabolism. The accumulation of polyphenols and anthocyanins evidenced an interesting trend showing an initial positive step linked to a new polyphenol and anthocyanin synthesis (such phenomenon regarding polyphenols did not occur in 2017) followed by a more stable phase (up to -20\% WL). Finally, a third phase took place with the accumulation of new colour compounds due to the concentration process. Specifically, NC tended to have more of both components than C 
during the withering process and, at $-30 \% \mathrm{WL}$, significant differences were found in favour of NC. Also, in this case, NC confirmed a higher accumulation capability, probably due to a slower and less stressful withering process linked to the higher temperature in $C$, capable of decreasing the synthesis or increasing the degradation of polyphenols and anthocyanins as confirmed previously by Shaked [59].

Stilbenes are characterized by several positive biological activities in human health $[22,60]$. Several studies have demonstrated that osmotic stress occurring during withering, which is induced by water loss and the higher temperatures of the chamber $\left(30{ }^{\circ} \mathrm{C}\right)$, stimulates stilbenes biosynthesis $[15,18-21,59,62]$. Therefore, a higher stilbene level is considered positive as it increases the health benefits of wine, particularly red wine. For our study, only visually healthy grapes, including berries affected by little, or no stilbene-oxidase activity caused by (e.g.) botrytis infections, were collected.

Consequently, differences observed in the two drying processes were mainly related to the different dehydration conditions. In general, accumulation of stilbenes in the berry (Table S1) up to $-20 \%$ WL was higher in the NC samples compared to the C ones, but in the latter case, the biosynthesis of stilbenes accelerated suddenly in the final withering stage (between 20-30\% WL) by increasing their level in the berry, in particular in 2017. Reasonably, the higher air humidity and lower temperature occurring in the NC process induce a longer time to reach a $-30 \%$ WL in the berry (Figure 3) by reducing cell stress in the initial withering stages. On the other hand, marked differences were observed between the two harvests. Grapes collected in the first year had higher initial stilbene content (Figure 9), and the stilbene accumulation trend during withering was different: against a steady increase observed in 2016, low accumulation was found up to $-20 \% \mathrm{WL}$ in 2017.

In the glycoside aroma precursors profile aliphatic alcohols found in both years to be increased by withering were butanol, 3-methyl-1-butanol, hexanol and 2-hexenol (Table S3). In general, these compounds account for herbaceous and unripe fruit aromas, and the wine tasting can reveal their presence [22]. cis-8-Hydroxy-linalool, geranic acid and 7 -hydroxy- $\alpha$-terpineol were the main monoterpenes that increased at $-30 \% \mathrm{WL}$ in both withering processes in both years. This class of aroma compounds is characteristic of Amarone wines, with geraniol as the main compound [63]. Significant is the presence of $\alpha$-terpineol in Corvina grapes (floral note); however, the slight increase observed at the end of withering can be linked to the chemical mechanisms of rearrangement of other monoterpenols occurring during the process $[64,65]$.

$\mathrm{C}_{13}$-Norisoprenoids contribute to the aromas of the Amarone with notes of ripe fruit, honey, jam, tea, and tobacco. In both years, the glycoside derivatives of 3-hydroxy- $B$ damascenone, 3-oxo- $\alpha$-ionol, and vomifoliol had the highest concentrations in NC (in 2017, at the end of the process, a 2-fold increase was found with a significant difference between the treatments).

In 2016, glycoside benzenoids (spicy, balsamic aromas) such as methyl salicylate, guaiacol, benzyl alcohol, $\$$-phenylethanol, syringol, vanillin, and vanillic alcohol had a 2 -fold increase in both $\mathrm{C}$ and NC processes. In both the dehydration processes, the highest amount of benzenoids in the berry was found at $-30 \% \mathrm{WL}$, particularly benzyl alcohol, guaiacol, syringol, vanillin, acetovanillone, and vanillic alcohol. In 2017 at $-30 \%$ WL, the NC treatment evidenced the highest quantity in benzenoids due to the high level in benzyl alcohol, guaiacol, syringol, vanillin, acetovanillone, eugenol, and vanillic alcohol (Table S3), and all together can contribute to the typical aroma of Amarone wines. 
In both years, the content of 4-vinylguaiacol at -30\% WL (spicy note; sensory threshold in wine $40 \mu \mathrm{g} / \mathrm{L}$ [66] was statistically different between the two processes $(p<0.05$ and $p<0.001$ in 2016 and 2017, respectively) with higher contents in NC samples (data not shown)._The low benzaldehyde level found in the samples compared to benzyl alcohol (between 20-50 $\mu \mathrm{g} / \mathrm{kg} \mathrm{d.g.} \mathrm{and} \mathrm{800-2500} \mathrm{\mu g/} \mathrm{kg} \mathrm{d.g.,} \mathrm{respectively)} \mathrm{indicates} \mathrm{that} \mathrm{low} \mathrm{or} \mathrm{no}$ oxidative processes occurred due to Botrytis cinerea infection [67].

In general, the drying process carried out in NC conditions was slower than in $\mathrm{C}$ due to higher $\mathrm{RH}$, lower $\mathrm{T}$, and air forced movement in the $\mathrm{C}$ environment. This slower process led to a major accumulation of sugars (i.e., 2017 vintage), polyphenols and anthocyanins in NC. It is assumed that the slower process in NC was able to maintain vital cell structures for longer, with less water stress effects (lesser synthesis of stilbenes can confirm this observation). In terms of total aroma compounds (Table 1), we found a higher content in NC, also confirmed by the better wine profile of these wines. Finally, to reach a considerable content of compounds and obtain balanced wines, we can report that it is desirable to reach a $-30 \%$ WL and adopt NC conditions. The present research confirmed that slowing down the drying process and creating less stressful conditions for the cells could be a strategic option to achieve a more traditional and wellappreciated Amarone wine and that choosing the traditional drying process carried out in natural conditions could also improve overall market appreciation.

\section{Conclusions}

The positive correlation between the slow rate of water loss and the total number of activated genes has already been reported for berries under different maintenance procedures affecting the total length of the post-harvest process [68,69]. These experiences emphasized that the longer the period of berry dehydration, the higher the transcriptional modulation, which in turn influences the metabolomic profile of the dried grapes.

Furthermore, we can assume that the grape ripening level at the beginning of the drying process can play a role in the subsequent berry chemical composition. In fact, in 2016, where we found more sugars and anthocyanins at T0, at $-20 \% \mathrm{WL}$, we observed more colour, stilbenes and the final level of the aroma compounds. Specifically, this occurred mostly for $\mathrm{C}$ in terms of sugar, anthocyanins, and aroma composition. For NC, especially in the vintage less favourable in terms of grape quality (for instance, in 2017 sugar and anthocyanins T0 levels were lower than in 2016), the slow down drying resulted more suitable to produce grapes characterized by higher levels of VOC glycoside precursors, anthocyanins and polyphenols, and wines with higher complexity where olfactory notes harmonize well with wine alcohol content. Sensory evaluation of wines highlighted the positive sensory descriptors present in the wines produced adopting the NC process, since, as a general trend, the panel found this wine to be more harmonious, elegant, and balanced and displaying more ripe, red fruit and spicy notes and less herbaceous nuances (with significant scores for ripe fruit, smooth and spicy notes), than that wines from grapes dehydrated in $\mathrm{C}$ conditions. 


\section{Supplementary Materials:}

\begin{tabular}{lc}
\multicolumn{1}{c}{ stilbenes identified } & signal intensity \\
trans-resveratrol & 169027 \\
piceatannol & 490372 \\
cis-piceid & 34732 \\
trans-piceid & 35455 \\
E-astringin & 19778 \\
$Z$-astringin & 5072 \\
pallidol & 11191 \\
resveratrol dimer & 5555 \\
Z- $\varepsilon$-viniferin & 122415 \\
$Z$ - $\omega$-viniferin & 19796 \\
$E$ - $\varepsilon$-viniferin & 582239 \\
$\delta$-viniferin & 8816 \\
caraphenol & 24940 \\
pallidol-glucoside & 24020 \\
$\alpha$-viniferin & 1848 \\
$Z$ - miyabenol C & 4538 \\
E-miyabenol C & 26439 \\
resveratrol tetramer 1 & 5076 \\
resveratrol tetramer 2 & 16480 \\
\hline
\end{tabular}

Table S1. Stilbenes identified in Corvina grape before withering. Signal intensities are normalized to the internal standard. 


\begin{tabular}{|c|c|c|c|c|c|c|c|c|c|c|c|c|c|c|}
\hline \multirow{4}{*}{2016} & \multicolumn{14}{|c|}{ ( $\mu$ g 1-heptanol/Kg d.g.) } \\
\hline & \multicolumn{2}{|c|}{ TO } & \multicolumn{4}{|c|}{$-10 \% \mathrm{WL}$} & \multicolumn{4}{|c|}{$-20 \% W L$} & \multicolumn{4}{|c|}{$-30 \% \mathrm{WL}$} \\
\hline & \multirow[b]{2}{*}{ Mean } & \multirow[b]{2}{*}{ STD } & \multicolumn{2}{|c|}{ C } & \multicolumn{2}{|c|}{ NC } & \multicolumn{2}{|l|}{ C } & \multicolumn{2}{|c|}{$\mathrm{NC}$} & $\mathrm{C}$ & & $\mathrm{NC}$ & \\
\hline & & & Mean & STD & Mean & STD & Mean & STD & Mean & STD & Mean & STD & Mean & STD \\
\hline aliphatic alcohols & & & & & & & & & & & & & & \\
\hline 1-butanol & 48 & 18 & 87 & 19 & 64 & 3 & 101 & 8 & 101 & 12 & 92 & 30 & 97 & 4 \\
\hline 3-methyl-1-butanol & 47 & 15 & 105 & 50 & 64 & 27 & 211 & 53 & 87 & 28 & 150 & 60 & 94 & 42 \\
\hline 3-methy-3-buten-1-ol & 25 & 4 & 33 & 3 & 30 & 6 & 36 & 4 & 38 & 3 & 33 & 11 & 36 & 1 \\
\hline 1-pentanol & 7 & 1 & 13 & 3 & 8 & 2 & 16 & 6 & 11 & 1 & 17 & 1 & 14 & 3 \\
\hline 3-methyl-2-buten-1-ol & 61 & 10 & 88 & 16 & 76 & 17 & 107 & 15 & 91 & 11 & 93 & 21 & 99 & 11 \\
\hline 1-hexanol & 69 & 18 & 77 & 19 & 56 & 4 & 110 & 18 & 74 & 17 & 113 & 71 & 119 & 55 \\
\hline 3-hexen-1-ol (E) & 1 & 0 & 1 & 0 & 1 & 0 & 3 & 1 & 1 & 1 & 2 & 1 & 2 & 1 \\
\hline 3-hexen-1-ol (Z) & 22 & 6 & 17 & 1 & 14 & 3 & 20 & 2 & 15 & 5 & 17 & 6 & 17 & 4 \\
\hline 2-butoxyethanol & 6 & 2 & 11 & 1 & 11 & 1 & 152 & 128 & 137 & 32 & 40 & 36 & 37 & 23 \\
\hline 2-hexenol & 11 & 2 & 12 & 2 & 11 & 2 & 16 & 9 & 15 & 5 & 18 & 8 & 18 & 2 \\
\hline$C_{6}$-aldehydes & & & & & & & & & & & & & & \\
\hline hexanal & 13 & 3 & 23 & 2 & 29 & 11 & 27 & 11 & 25 & 11 & 13 & 5 & 20 & 3 \\
\hline 2-hexenal & 14 & 3 & 20 & 3 & 26 & 9 & 14 & 5 & 21 & 7 & 9 & 4 & 15 & 1 \\
\hline monoterpenes & & & & & & & & & & & & & & \\
\hline trans-furanlinalool oxide & 2 & 0 & 3 & 1 & 2 & 1 & 3 & 1 & 3 & 1 & 3 & 1 & 3 & 2 \\
\hline cis-furanlinalool oxide & 2 & 0 & 3 & 0 & 2 & 1 & 3 & 0 & 2 & 1 & 2 & 1 & 2 & 1 \\
\hline linalool & 15 & 7 & 14 & 1 & 13 & 5 & 6 & 0 & 18 & 4 & 8 & 4 & 10 & 3 \\
\hline$\alpha$-terpineol & 3 & 0 & 5 & 1 & 3 & 1 & 5 & 1 & 4 & 1 & 4 & 1 & 4 & 3 \\
\hline trans-pyranlinalool oxide & 8 & 2 & 11 & 2 & 8 & 5 & 12 & 2 & 11 & 4 & 11 & 4 & 11 & 7 \\
\hline nerol & 16 & 1 & 24 & 4 & 18 & 4 & 21 & 6 & 22 & 2 & 19 & 6 & 20 & 1 \\
\hline geraniol & 69 & 7 & 100 & 7 & 88 & 20 & 95 & 11 & 97 & 9 & 87 & 23 & 92 & 6 \\
\hline 2-exo-2-hydroxycineol & 9 & 3 & 11 & 2 & 11 & 5 & 13 & 3 & 13 & 4 & 14 & 7 & 13 & 4 \\
\hline diendiol I & 10 & 3 & 10 & 2 & 11 & 5 & 10 & 3 & 12 & 4 & 11 & 6 & 9 & 3 \\
\hline trans-8-hydroxylinalool & 39 & 17 & 73 & 17 & 50 & 13 & 68 & 21 & 61 & 4 & 77 & 7 & 59 & 20 \\
\hline hydroxygeraniol & 19 & 2 & 37 & 6 & 26 & 8 & 44 & 3 & 36 & 5 & 37 & 10 & 41 & 5 \\
\hline cis-8-hydroxylinalool & 104 & 31 & 132 & 24 & 90 & 48 & 128 & 33 & 143 & 20 & 134 & 32 & 125 & 45 \\
\hline geranic acid & 56 & 6 & 116 & 11 & 91 & 12 & 107 & 11 & 120 & 9 & 106 & 25 & 116 & 9 \\
\hline 7-hydroxy- $\alpha$-terpineol & 203 & 105 & 268 & 81 & 280 & 167 & 345 & 121 & 335 & 166 & 344 & 230 & 308 & 74 \\
\hline$C_{13}$-norisoprenoids & & & & & & & & & & & & & & \\
\hline 3-hydroxy- $\beta$-damascenone & 35 & 6 & 41 & 8 & 35 & 9 & 50 & 9 & 40 & 7 & 43 & 12 & 46 & 14 \\
\hline 3-oxo- $\alpha$-ionol & 331 & 35 & 485 & 55 & 385 & 92 & 502 & 41 & 511 & 10 & 467 & 43 & 488 & 91 \\
\hline 3,9-dihydroxy-megastigma-5-ene & 28 & 5 & 35 & 4 & 26 & 6 & 38 & 3 & 35 & 1 & 37 & 6 & 36 & 8 \\
\hline 3-hydroxy-7,8-dihydro- $\alpha$-ionol & 23 & 3 & 33 & 6 & 29 & 7 & 36 & 2 & 35 & 3 & 36 & 9 & 35 & 2 \\
\hline vomifoliol & 368 & 81 & 510 & 115 & 439 & 92 & 524 & 85 & 556 & 39 & 543 & 90 & 538 & 107 \\
\hline benzenoids & & & & & & & & & & & & & & \\
\hline benzaldehyde & 46 & 53 & 36 & 27 & 18 & 2 & 26 & 11 & 20 & 9 & 22 & 9 & 17 & 5 \\
\hline acetophenone & 6 & 6 & 6 & 2 & 5 & 2 & 6 & 2 & 7 & 1 & 6 & 2 & 8 & 3 \\
\hline methyl salicilate & 15 & 15 & 15 & 8 & 9 & 3 & 13 & 6 & 10 & 2 & 9 & 1 & 12 & 7 \\
\hline guaiacol & 5 & 2 & 26 & 11 & 9 & 4 & 22 & 4 & 10 & 4 & 19 & 8 & 15 & 7 \\
\hline benzyl alcohol & 590 & 173 & 799 & 207 & 1100 & 269 & 924 & 151 & 1345 & 590 & 964 & 213 & 1337 & 541 \\
\hline$\beta$-phenylethanol & 276 & 26 & 391 & 96 & 404 & 85 & 478 & 64 & 447 & 63 & 418 & 135 & 436 & 39 \\
\hline eugenol & 20 & 3 & 29 & 5 & 29 & 3 & 34 & 4 & 37 & 3 & 28 & 6 & 33 & 5 \\
\hline 4-vinylguaiacol & 375 & 76 & 808 & 186 & 800 & 107 & 993 & 68 & 900 & 42 & 841 & 201 & 999 & 161 \\
\hline syringol & 58 & 12 & 275 & 86 & 83 & 41 & 228 & 70 & 87 & 33 & 176 & 75 & 127 & 56 \\
\hline 4-vinylphenol & 105 & 47 & 404 & 207 & 380 & 99 & 402 & 29 & 379 & 85 & 219 & 23 & 409 & 110 \\
\hline vanillin & 30 & 6 & 54 & 15 & 48 & 5 & 66 & 8 & 51 & 6 & 56 & 16 & 55 & 2 \\
\hline methyl vanillate & 42 & 15 & 54 & 13 & 51 & 21 & 67 & 16 & 59 & 13 & 59 & 23 & 53 & 8 \\
\hline acetovanillone & 297 & 45 & 443 & 115 & 482 & 67 & 512 & 88 & 580 & 114 & 478 & 123 & 619 & 154 \\
\hline vanillic alcohol & 267 & 48 & 620 & 335 & 625 & 42 & 760 & 213 & 724 & 155 & 601 & 111 & 815 & 243 \\
\hline homovanillic alcohol & 196 & 46 & 416 & 134 & 394 & 51 & 437 & 85 & 509 & 59 & 467 & 131 & 539 & 11 \\
\hline 4-hydroxy benzene ethanol & 70 & 24 & 260 & 107 & 291 & 20 & 317 & 98 & 307 & 43 & 248 & 83 & 330 & 64 \\
\hline furanic compounds & & & & & & & & & & & & & & \\
\hline 5-methylfurfural & 27 & 8 & 43 & 7 & 42 & 3 & 48 & 6 & 57 & 1 & 43 & 15 & 54 & 1 \\
\hline 2-furanmethanol & 26 & 3 & 59 & 11 & 50 & 3 & 66 & 16 & 66 & 2 & 55 & 10 & 70 & 3 \\
\hline furaneol & 53 & 9 & 102 & 18 & 92 & 5 & 114 & 22 & 123 & 1 & 99 & 22 & 124 & 4 \\
\hline
\end{tabular}

Table S2. Contents of glycoside precursors of volatile organic compounds (VOCs) identified in Corvina grapes harvested in 2016 and withered in controlled (C) and not-controlled (NC) environments (data expressed as $\mu \mathrm{g}$ 1-heptanol $/ \mathrm{kg} \mathrm{d.g.).}$ 


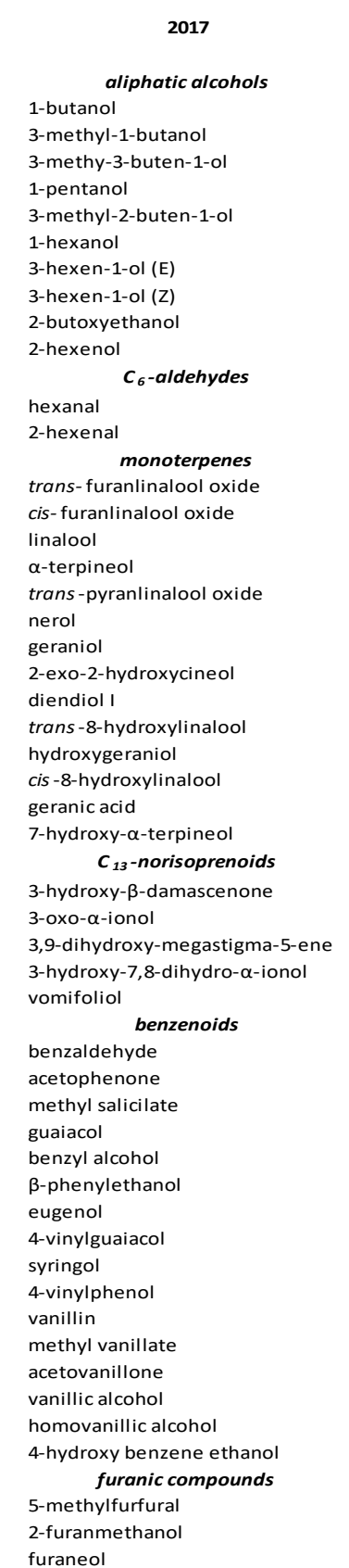

\begin{tabular}{|c|c|c|c|c|}
\hline \multirow{3}{*}{ TO } & \multicolumn{4}{|c|}{ ( $\mu$ g 1-heptanol/Kg d.g.) } \\
\hline & -10 & $6 \mathrm{WL}$ & & $-20 \% W L$ \\
\hline & C & NC & C & NC \\
\hline Mean STD & Mean STD & Mean STD & Mean & STD Mean STD \\
\hline
\end{tabular}

$\frac{-\mathbf{3 0 \%} \mathbf{W L}}{\text { Mean STD Mean STD }}$

$\begin{array}{cccccccccc}74 & 24 & 76 & 17 & 68 & 9 & 76 & 9 & 94 & 49 \\ 79 & 19 & 117 & 111 & 76 & 16 & 99 & 30 & 118 & 5 \\ 40 & 4 & 33 & 2 & 36 & 2 & 35 & 2 & 43 & 8 \\ 11 & 5 & 5 & 0 & 7 & 2 & 8 & 1 & 10 & 4 \\ 108 & 14 & 101 & 11 & 104 & 12 & 108 & 19 & 136 & 30 \\ 72 & 8 & 62 & 16 & 62 & 22 & 59 & 14 & 89 & 25 \\ 1 & 0 & 1 & 0 & 1 & 0 & 1 & 0 & 2 & 1 \\ 33 & 4 & 16 & 3 & 23 & 10 & 13 & 5 & 21 & 4 \\ 62 & 45 & 123 & 69 & 78 & 96 & 51 & 32 & 30 & 15 \\ 7 & 2 & 5 & 2 & 4 & 1 & 7 & 2 & 9 & 3\end{array}$

$\begin{array}{llll}112 & 41 & 174 & 58\end{array}$ $\begin{array}{llll}161 & 109 & 225 & 39\end{array}$

$\begin{array}{llll}45 & 3 & 45 & 9\end{array}$

$\begin{array}{llll}8 & 1 & 16 & 7\end{array}$

$\begin{array}{llll}112 & 17 & 87 & 77\end{array}$

$\begin{array}{llll}86 & 33 & 153 & 27\end{array}$

$\begin{array}{llll}2 & 1 & 3 & 1\end{array}$

$\begin{array}{llll}14 & 9 & 23 & 2\end{array}$

$95 \quad 79 \quad 76 \quad 71$

$\begin{array}{cccccccccccccc}31 & 15 & 38 & 13 & 48 & 7 & 110 & 45 & 124 & 59 & 49 & 13 & 89 & 29 \\ 28 & 7 & 18 & 6 & 22 & 2 & 11 & 4 & 14 & 1 & 16 & 4 & 16 & 2\end{array}$

$4 \quad 1$

$\begin{array}{llll}3 & 2 & 5 & 1\end{array}$

$\begin{array}{llllllll}5 & 4 & 8 & 4 & 3 & 2 & 8 & 2 \\ 6 & 4 & 8 & 4 & 3 & 2 & 8 & 3\end{array}$

$\begin{array}{llllllllllllll}3 & 0 & 3 & 1 & 5 & 2 & 6 & 4 & 8 & 4 & 3 & 2 & 8 & 3\end{array}$

$\begin{array}{cccccccccccccc}49 & 12 & 34 & 11 & 40 & 4 & 36 & 19 & 39 & 6 & 19 & 7 & 39 & 37 \\ 5 & 0 & 5 & 2 & 7 & 3 & 7 & 5 & 12 & 4 & 5 & 3 & 11 & 2\end{array}$

$\begin{array}{llllllllllllll}12 & 2 & 12 & 5 & 14 & 3 & 14 & 6 & 22 & 10 & 9 & 6 & 22 & 4\end{array}$

$\begin{array}{llllllllllllll}19 & 3 & 15 & 7 & 17 & 4 & 14 & 6 & 20 & 5 & 16 & 5 & 21 & 3\end{array}$

$\begin{array}{llllllllllllll}79 & 14 & 66 & 28 & 76 & 19 & 61 & 26 & 82 & 19 & 80 & 23 & 87 & 21\end{array}$

$\begin{array}{llllllllllllll}12 & 3 & 11 & 5 & 14 & 2 & 14 & 5 & 16 & 2 & 14 & 6 & 24 & 7\end{array}$

$\begin{array}{llllllllllllll}12 & 3 & 10 & 6 & 13 & 4 & 12 & 5 & 15 & 6 & 10 & 8 & 9 & 5\end{array}$

$\begin{array}{llllllllllllll}52 & 9 & 42 & 12 & 73 & 18 & 43 & 11 & 106 & 78 & 45 & 30 & 86 & 68\end{array}$

$\begin{array}{llllllllllllll}25 & 6 & 21 & 6 & 35 & 11 & 32 & 14 & 49 & 20 & 31 & 13 & 51 & 6\end{array}$

$\begin{array}{llllllllllllll}228 & 60 & 162 & 27 & 220 & 38 & 137 & 24 & 209 & 44 & 123 & 33 & 173 & 14\end{array}$

$\begin{array}{llllllllllllll}49 & 10 & 54 & 16 & 84 & 13 & 44 & 13 & 74 & 27 & 108 & 20 & 109 & 22\end{array}$

$\begin{array}{llllllllllllll}188 & 46 & 185 & 120 & 225 & 30 & 214 & 92 & 251 & 45 & 232 & 117 & 249 & 31\end{array}$

$\begin{array}{llllll}51 & 7 & 55 & 8 & 64 & 5\end{array}$

54163

$\begin{array}{llll}466 & 178 & 737 & 49\end{array}$

$\begin{array}{llll}66 & 13 & 84 & 22\end{array}$

$\begin{array}{llll}733 & 150 & 878 & 214\end{array}$

$\begin{array}{llll}47 & 10 & 109 & 46\end{array}$

$\begin{array}{llllll}31 & 3 & 35 & 5 & 36 & 4\end{array}$

$28 \quad 3$

$422 \quad 101$

$\begin{array}{llll}377 & 52 & 592 & 79\end{array}$

$\begin{array}{llll}31 & 5 & 41 & 17\end{array}$

$\begin{array}{llll}31 & 4 & 37 & 5\end{array}$

$\begin{array}{llll}562 & 100 & 1340 \quad 575\end{array}$

$\begin{array}{llll}25 & 9 & 40 & 6\end{array}$

$\begin{array}{llll}33 & 5 & 48 & 10\end{array}$

$\begin{array}{llll}497 & 99 & 1167 & 448\end{array}$

\section{$39 \quad 17$}

$\begin{array}{ll}6 & 1 \\ 4 & 2\end{array}$

$\begin{array}{cc}4 & 2 \\ 125 & 24\end{array}$

$572 \quad 41$

$370 \quad 41$

$24 \quad 2$

$578 \quad 99$

$160 \quad 31$

265126

$48 \quad 5$

165

$268 \quad 24$

$239 \quad 73$

$\begin{array}{llll}30 & 7 & 20 & 2\end{array}$

$623 \quad 202 \quad 928 \quad 308$

$\begin{array}{cccccccc}50 & 19 & 32 & 15 & 34 & 16 & 43 & 25 \\ 8 & 3 & 7 & 6 & 6 & 3 & 15 & 14\end{array}$ $\begin{array}{llllllll}8 & 3 & 6 & 1 & 6 & 0 & 24 & 18\end{array}$ $\begin{array}{cccccccccccc}6 & 1 & 3 & 1 & 8 & 3 & 6 & 1 & 6 & 0 & 24 & 18 \\ 111 & 104 & 139 & 32 & 243 & 259 & 576 & 324 & 222 & 192 & 799 & 266\end{array}$ $\begin{array}{llllllllllll}748 & 117 & 662 & 170 & 1263 & 259 & 1031 & 242 & 1484 & 360 & 1936 & 942\end{array}$ $\begin{array}{llllllll}412 & 99 & 456 & 49 & 368 & 54 & 453 & 113\end{array}$ $\begin{array}{llllllll}28 & 2 & 28 & 6 & 23 & 5 & 30 & 10\end{array}$ $\begin{array}{llllllll}493 & 120 & 583 & 85 & 467 & 94 & 746 & 196\end{array}$ $\begin{array}{llllllll}145 & 72 & 241 & 128 & 344 & 296 & 741 & 286\end{array}$ $\begin{array}{llllllll}135 & 103 & 228 & 54 & 281 & 129 & 579 & 219\end{array}$ $\begin{array}{llllllll}68 & 18 & 78 & 16 & 99 & 25 & 137 & 17\end{array}$ $\begin{array}{llllllll}18 & 7 & 25 & 2 & 20 & 10 & 33 & 9\end{array}$ $\begin{array}{llllllll}240 & 192 & 377 & 68 & 321 & 14 & 467 & 132\end{array}$ $\begin{array}{llllllll}324 & 71 & 422 & 35 & 517 & 139 & 754 & 154\end{array}$ $\begin{array}{llllllll}381 & 67 & 358 & 114 & 390 & 42 & 518 & 136\end{array}$ $\begin{array}{llll}457 & 90 & 593 & 60\end{array}$ $\begin{array}{llll}28 & 8 & 55 & 22\end{array}$ $\begin{array}{llll}736 & 159 & 1092 & 139\end{array}$ $\begin{array}{llll}253 & 235 & 825 & 291\end{array}$ $\begin{array}{llll}688 & 312 & 513 & 192\end{array}$ $\begin{array}{llll}93 & 21 & 154 & 47\end{array}$ $\begin{array}{llll}21 & 7 & 43 & 14\end{array}$ $\begin{array}{llll}340 & 61 & 744 & 262\end{array}$ $\begin{array}{llll}641 & 198 & 1079 & 430\end{array}$ $\begin{array}{llll}518 & 61 & 624 & 93\end{array}$ $\begin{array}{llll}411 & 111 & 158 & 175\end{array}$ $\begin{array}{llllll}196 & 51 & 112 & 129 & 70 & 10\end{array}$

Table S3. Contents of glycoside precursors of volatile organic compounds (VOCs) identified in Corvina grapes harvested in 2017 and withered in controlled (C) and not-controlled (NC) environments (data expressed as $\mu \mathrm{g}$ 1-heptanol/kg d.g.). 
Author Contributions: Conceptualization, D.T. and A.L; methodology, D.T. and L.L.; software, G.M., D.B.; validation, D.T., G.M. and D.B.; formal analysis, G.M.; investigation, C.M.M., M.DR., R.F., T.N., L.L.; resources, A.L.; data curation, C.M.M., M.DR., R.F., D.B., G.M and D.T.; writingoriginal draft preparation, G.M., R.F., D.B., D.T. and T.N.; writing-review and editing, G.M., R.F., D.T., D.B., T.N.; visualization, D.B.; supervision, D.T.; project administration, D.T.; funding acquisition, D.T. All authors have read and agreed to the published version of the manuscript.

Funding: This research was funded entirely by “Bertani Domains Società Agricola A R.L., Grezzana, Verona (Italy).

Acknowledgments: The Authors thank Bertani Domains Società Agricola A R.L. for founding the research entirely and allowing us to conduct the experiments in their vineyards and withering chambers, providing all the support required.

Conflicts of Interest: The authors declare no conflict of interest.

\section{References}

1. 1. Fregoni, M. Viticoltura Di Qualità. Trattato Dell'eccellenza Da: Terroir; I.; Tecniche Nuove: Milano, 2013; ISBN 88-481-29196.

2. 2. Mencarelli, F.; Bellincontro, A. Recent Advances in Postharvest Technology of the Wine Grape to Improve the Wine Aroma. Journal of the Science of Food and Agriculture 2018, 100, doi:10.1002/jsfa.8910.

3. 3. Brennan, J.G. Food Dehydration: A Dictionary and Guide; CRC Press, 1997; ISBN 978-0-7506-1130-5.

4. 4. Potter, N.N.; Hotchkiss, J.H. Characteristics of the Food Industry. In Food Science: Fifth Edition; Potter, N.N., Hotchkiss, J.H., Eds.; Food Science Text Series; Springer US: Boston, MA, 1995; pp. 13-23 ISBN 978-1-4615-4985-7.

5. 5. Ramos, I.N.; Silva, C.L.M.; Sereno, A.M.; Aguilera, J.M. Quantification of Microstructural Changes during First Stage Air Drying of Grape Tissue. Journal of Food Engineering 2004, 62, 159-164, doi:10.1016/S0260-8774(03)00227-9.

6. 6. Serratosa, M.; Lopez-Toledano, A.; Medina, M.; Merida, J. Drying of Pedro Ximenez Grapes in Chamber at Controlled Temperature and with Dipping Pretreatments. Changes in the Color Fraction. Journal of agricultural and food chemistry 2008, 56, 10739-46, doi:10.1021/jf8021767.

7. 7. Barbanti, D.; Mora, B.; Ferrarini, R.; Tornielli, G. Battista; Cipriani, M. Effect of Various Thermo-Hygrometric Conditions on the Withering Kinetics of Grapes Used for the Production of "Amarone" and "Recioto" Wines. Journal of Food Engineering - J FOOD ENG 2008, 85, 350-358, doi:10.1016/j.jfoodeng.2007.07.003.

8. 8. Coombe, B.G.; Iland, P.G. Grape Berry Development and Winegrape Quality. Viticulture 2004, 1, $210-248$.

9. 9. Bellincontro, A.; Nicoletti, I.; Valentini, M.; Tomas, A.; Santis, D.; Corradini, D.; Mencarelli, F. Integration of Nondestructive Techniques with Destructive Analyses to Study Postharvest Water Stress of Winegrapes. American Journal of Enology and Viticulture 2009, 60, 57-65.

10. 10. Panceri, C.P.; Gomes, T.M.; De Gois, J.S.; Borges, D.L.G.; Bordignon-Luiz, M.T. Effect of dehydration process on mineral content, phenolic compounds and antioxidant activity of Cabernet Sauvignon and Merlot grapes. Food Res. Int. 2013, 54, 13431350, doi:10.1016/j.foodres.2013.10.016.

11. 11. Di Stefano Di, R.; Cravero, M.C. The grape phenolic determination. Rivista di Viticoltura e di Enologia 1991.

12. 12. Tonutti, P.; Mencarelli, F. Aspetti Fisiologici Di Disidratazione, Appassimento e Sovramaturazione Delle Uve Da Vino. L'informatore agrario 2005, Supplemento.

13. 13. Ortega-Regules, A.; Romero-Cascales, I.; López-Roca, J.M.; Ros-García, J.M.; Gómez-Plaza, E. Anthocyanin Fingerprint of Grapes: Environmental and Genetic Variations. Journal of the Science of Food and Agriculture 2006, 86, 1460-1467, doi:https://doi.org/10.1002/jsfa.2511.

14. 14. Bindon, K.A.; Bacic, A.; Kennedy, J.A. Tissue-Specific and Developmental Modifications of Grape Cell Walls Influence the Adsorption of Proanthocyanidins. J Agric Food Chem 2012, 60, 9249-9260, doi:10.1021/jf301552t.

15. 15. Versari, A.; Parpinello, G.P.; Tornielli, G.B.; Ferrarini, R.; Giulivo, C. Stilbene Compounds and Stilbene Synthase Expression during Ripening, Wilting, and UV Treatment in Grape Cv. Corvina. J. Agric. Food Chem. 2001, 49, 5531-5536, doi:10.1021/jf010672o.

16. 16. Frangipane, M.T.; Ceccarelli, A.; Mencarelli, F. Studio dei composti polifenolici in uve Aleatico sottoposte ad un nuovo sistema di appassimento. L' Enologo 2005, 41, 113-116.

17. 17. Frangipane, M.T.; Torresi, S.; Santis, D.; Massantini, R. Effect of Drying Process in Chamber at Controlled Temperature on the Grape Phenolic Compounds. Italian Journal of Food Science 2012, 24, 1-7.

18. 18. Zamboni, A.; Minoia, L.; Ferrarini, A.; Tornielli, G.B.; Zago, E.; Delledonne, M.; Pezzotti, M. Molecular Analysis of PostHarvest Withering in Grape by AFLP Transcriptional Profiling. J Exp Bot 2008, 59, 4145-4159, doi:10.1093/jxb/ern256.

19. 19. Mencarelli, F.; Bellincontro, A.; Nicoletti, I.; Cirilli, M.; Muleo, R.; Corradini, D. Chemical and Biochemical Change of Healthy Phenolic Fractions in Winegrape by Means of Postharvest Dehydration. J. Agric. Food Chem. 2010, 58, 7557-7564, doi:10.1021/jf100331z. 
20. 20. Nicoletti, I.; Bellincontro, A.; Rossi, A.D.; Sanctis, F.D.; Tiberi, D.; Pietromarchi, P.; Botondi, R.; Corradini, D.; Mencarelli, F. Postharvest Dehydration of Nebbiolo Grapes Grown at Altitude Is Affected by Time of Defoliation. Australian Journal of Grape and Wine Research 2013, 19, 358-368, doi:https://doi.org/10.1111/ajgw.12042.

21. 21. De Rosso, M.; Soligo, S.; Panighel, A.; Carraro, R.; Vedova, A.D.; Maoz, I.; Tomasi, D.; Flamini, R. Changes in Grape Polyphenols (V. Vinifera L.) as a Consequence of Post-Harvest Withering by High-Resolution Mass Spectrometry: Raboso Piave versus Corvina. Journal of Mass Spectrometry 2016, 51, 750-760, doi:https://doi.org/10.1002/jms.3835.

22. 22. Flamini R., M. De Rosso. High-Resolution Mass Spectrometry and Biological Properties of Grapevine and Wine Stilbenoids. In: Studies in Natural Product Chemistry Vol. 61, Chapter 5, Pages 175-210, Editor: Atta-Ur-Rahman (2018). Elsevier (https://doi.org/10.1016/B978-0-444-64183-0.00005-1) ISBN: 978-0-444-64183-0

23. 23. Noguerol-Pato, R.; González-Álvarez, M.; González-Barreiro, C.; Cancho-Grande, B.; Simal-Gándara, J. Evolution of the Aromatic Profile in Garnacha Tintorera Grapes during Raisining and Comparison with That of the Naturally Sweet Wine Obtained. Food Chem 2013, 139, 1052-1061, doi:10.1016/j.foodchem.2012.12.048.

24. 24. D'Onofrio, C. Changes in Volatile Compounds. In Sweet, Reinforced and Fortified Wines; John Wiley \& Sons, Ltd, 2013; pp. 91-103 ISBN 978-1-118-56918-4.

25. 25. Zhang, P.; Fuentes, S.; Siebert, T.; Krstic, M.; Herderich, M.; Barlow, E.W.R.; Howell, K. Terpene Evolution during the Development of Vitis Vinifera L. Cv. Shiraz Grapes. Food Chem 2016, 204, 463-474, doi:10.1016/j.foodchem.2016.02.125.

26. 26. Cirilli, M.; Bellincontro, A.; De Santis, D.; Botondi, R.; Colao, M.C.; Muleo, R.; Mencarelli, F. Temperature and Water Loss Affect ADH Activity and Gene Expression in Grape Berry during Postharvest Dehydration. Food Chem 2012, 132, 447-454, doi:10.1016/j.foodchem.2011.11.020.

27. 27. Moreno, J.J.; Cerpa-Calderón, F.; Cohen, S.D.; Fang, Y.; Qian, M.; Kennedy, J.A. Effect of Postharvest Dehydration on the Composition of Pinot Noir Grapes (Vitis Vinifera L.) and Wine. Food Chem 2008, 109, 755-762, doi:10.1016/j.foodchem.2008.01.035.

28. 28. Franco, M.; Peinado, R.A.; Medina, M.; Moreno, J. Off-Vine Grape Drying Effect on Volatile Compounds and Aromatic Series in Must from Pedro Ximénez Grape Variety. J. Agric. Food Chem. 2004, 52, 3905-3910, doi:10.1021/jf0354949.

29. 29. Genovese, A.; Gambuti, A.; Piombino, P.; Moio, L. Sensory Properties and Aroma Compounds of Sweet Fiano Wine. Food Chemistry 2007, 103, 1228-1236, doi:10.1016/j.foodchem.2006.10.027.

30. 30. MIIPAF; Reg, $n^{\circ} 558533 / 2019$.

31. 31. Cramer, G.R.; Ghan, R.; Schlaucht, K.A.; Tillett, R.L.; Heymann, H.; Ferrarini, A.; Delledonne, M.; Zenoni, S.; Fasoli, M.; Pezzotti, M. Transcriptomic Analysis of the Late Stages of Grapevine (Vitis Vinifera Cv. Cabernet Sauvignon) Berry Ripening Reveals Significant Induction of Ethylene Signaling and Flavor Pathways in the Skin I BMC Plant Biology | Full Text. BMC Plant Biology 2014, 1-21, doi:https://doi.org/10.1186/s12870-014-0370-8.

32. 32. Zenoni, S.; Fasoli, M.; Guzzo, F. Disclosing the Molecular Basis of the Postharvest Life of Berry in Different Grapevine Genotypes - PubMed. Plant Physiology 2016, 1821-1843, doi:10.1104/pp.16.00865.

33. 33. Ferrarini, R. L'effetto Appassimento Su Corvina, Corvinone e Rondinella. L'enologo 2014, 26-34.

34. 34. Di Stefano, R. (1991). Proposition d'une methode de preparation de l'echantillon pour la determination des terpenes libres et glycosides des raisins et des vins, Bull. O.I.V., 64 (721 - 722), 219 - 223).

35. 35. J. J. Mateo, N. Gentilini, T. Huerta, M. Jimenez, R. Di Stefano. Fractionation of glycoside precursors of aroma in grapes and wine. J. Chromatogr. A 1997, 778, 219;

36. 36. R. Flamini, P. Traldi. In Applications of Mass Spectrometry in Grape \& Wine, R. Flamini, P. Traldi (Eds). John Wiley \& Sons Inc.: Hoboken, 2010, pp. 97-116;

37. 37. Bavaresco L., Petegolli D., Cantù E., Fregoni M., Chiusa G., Trevisan M. Elicitation and accumulation of stilbene phytoalexins in grapevine berries infected by Botrytis cinerea. Vitis, 1997, 36 (2), 77-83

38. 38. Repetto O., Bertazzon N., De Rosso M., Miotti L., Flamini R., Angelini E., Borgo M. Low susceptibility of grapevine infected by GLRaV-3 to late Plasmopara viticola infections: towards the understanding. Physiological and Molecular Plant Pathology 79:55-63 (2012) (DOI: 10.1016/j.pmpp.2012.04.001)

39. 39. R. Pezet, C. Perret, J.B. Jean-Denis, R. Tabacchi, K. Gindro, O. Viret. $\delta$-Viniferin, a resveratrol dehydrodimer: one of the major stilbenes synthesized by stressed grapevine leaves. J. Agric. Food Chem., 51 (2003), pp. 5488-5492.

40. 40. Flamini R., M. De Rosso, F. De Marchi, A. Dalla Vedova, A. Panighel, M. Gardiman, I. Maoz, L. Bavaresco. An innovative approach to grape metabolomics: stilbene profiling by suspect screening analysis. Metabolomics 9:1243-1253 (2013)

41. 41. Flamini R., A. Zanzotto, M. De Rosso, G. Lucchetta, A. Dalla Vedova, L. Bavaresco. Stilbene oligomer phytoalexins in grape as a response to Aspergillus carbonarius infection. Physiological and Molecular Plant Pathology 93:112-118 (2016)

42. 42. Alessandrini, M., Battista, F., Panighel, A., Flamini, R. and Tomasi, D. (2018), Effect of pre-bloom leaf removal on grape aroma composition and wine sensory profile of Semillon cultivar. J. Sci. Food Agric, 98: 16741684. https://doi.org/10.1002/jsfa.8638

43. 43. Sidel, J.L.; Stone, H. The Role of Sensory Evaluation in the Food Industry. Food Quality and Preference 1993, 4, 65-73, doi:10.1016/0950-3293(93)90314-V.

44. 44. Montgomery, D.C. Design and Analysis of Experiments; John Wiley \& Sons, 2017; ISBN 978-1-119-11347-8.

45. 45. Fasoli, M.; Dell' Anna, R.; Amato, A.; Balestrini, R.; Dal Santo, S.; Monti, F.; Zenoni, S. Active Rearrangements in the Cell Wall Follow Polymer Concentration during Postharvest Withering in the Berry Skin of Vitis Vinifera Cv. Corvina. Plant Physiol Biochem 2019, 135, 411-422, doi:10.1016/j.plaphy.2018.11.020. 
46. 46. Kays, S. Postharvest Physiology of Perishable Plant Products; Springer US, 1997; ISBN 978-1-888186-53-6.

47. 47. Rose, J.; Bennett, K.; Labavitch, J.; Bennett, A. Temporal Sequence of Cell Wall Disassembly in Rapidly Ripening Melon Fruit. Plant physiology 1998, 117, 345-61.

48. 48. Nunan, K.; Sims, I.; Bacic, A.; Robinson, S.; Fincher, G. Changes in Cell Wall Composition during Ripening of Grape Berries. Plant Physiol 1998, 118, 783-792, doi:10.1104/pp.118.3.783.

49. 49. Amati, A.; Ferrarini, R.; Riponi, C.; Zironi, R. Una Nuova Tecnologia per l'appassimento Delle Uve. Vigne Vini 1983, 27-35.

50. 50. Kennedy, J.; Matthews, M.; Waterhouse, A. Effect of Maturity and Vine Water Status on Grape Skin and Wine Flavonoids. American Journal of Enology and Viticulture 2002, 53, 268-274.

51. 51. Spayd, S.E.; Tarara, J.M.; Mee, D.L.; Ferguson, J.C. Separation of Sunlight and Temperature Effects on the Composition of Vitis Vinifera Cv. Merlot Berries. American Journal of Enology and Viticulture 2002, 53, 171-182.

52. 52. Dokoozlian, N.K.; Kliewer, W.M. Influence of Light on Grape Berry Growth and Composition Varies during Fruit Development. Journal of the American Society for Horticultural Science jashs 1996, 121, 869-874, doi:10.21273/JASHS.121.5.869.

53. 53. Keller, M.; Hrazdina, G. Interaction of Nitrogen Availability During Bloom and Light Intensity During Veraison. II. Effects on Anthocyanin and Phenolic Development During Grape Ripening. American Journal of Enology and Viticulture 1998, 49, 341-349.

54. 54. Ojeda, H.; Andary, C.; Kraeva, E.; Carbonneau, A.; Deloire, A. Influence of Pre- and Postveraison Water Deficit on Synthesis and Concentration of Skin Phenolic Compounds during Berry Growth of Vitis Vinifera Cv. Shiraz. American Journal of Enology and Viticulture 2002, 53, 261-267.

55. 55. Malacarne, G.; Costantini, L.; Coller, E.; Battilana, J.; Velasco, R.; Vrhovsek, U.; Grando, M.S.; Moser, C. Regulation of Flavonol Content and Composition in (Syrah $\times$ Pinot Noir) Mature Grapes: Integration of Transcriptional Profiling and Metabolic Quantitative Trait Locus Analyses. J Exp Bot 2015, 66, 4441-4453, doi:10.1093/jxb/erv243.

56. 56. Margaris, D.; Ghiaus, A. Experimental Study of Hot Air Dehydration of Sultana Grapes. Journal of Food Engineering 2007, 79, 1115-1121, doi:10.1016/j.jfoodeng.2006.03.024.

57. 57. Marquez, A.; Serratosa, M.P.; Lopez-Toledano, A.; Merida, J. Colour and Phenolic Compounds in Sweet Red Wines from Merlot and Tempranillo Grapes Chamber-Dried under Controlled Conditions. Food Chemistry 2012, 130, 111-120, doi:https://doi.org/10.1016/j.foodchem.2011.07.010.

58. 58. Zoccatelli, G.; Zenoni, S.; Savoi, S.; Santo, S.D.; Tononi, P.; Zandonà, V.; Cin, A.D.; Guantieri, V.; Pezzotti, M.; Tornielli, G.B. Skin Pectin Metabolism during the Postharvest Dehydration of Berries from Three Distinct Grapevine Cultivars. Australian Journal of Grape and Wine Research 2013, 19, 171-179, doi:https://doi.org/10.1111/ajgw.12014.

59. 59. Shaked-Sachray, L.; Weiss, D.; Reuveni, M.; Nissim-Levi, A.; Oren-Shamir, M. Increased Anthocyanin Accumulation in Aster Flowers at Elevated Temperatures Due to Magnesium Treatment. Physiol Plant 2002, 114, 559-565, doi:10.1034/j.13993054.2002.1140408.x.

60. 60. Guilford, J.M.; Pezzuto, J. Wine and Health: A Review. American Journal of Enology and Viticulture 2011, 62, 471-486.

61. 61. Brillante L., M. De Rosso, A. Dalla Vedova, I. Maoz, R. Flamini, D. Tomasi. Insights on the stilbenes in Raboso Piave grape (V. vinifera L.) as a consequence of post-harvest vs on-vine dehydration. J. Sci. Food Agric. 98(5):1961-1967 (2018) (DOI: 10.1002/jsfa.8679)

62. 62. Bonghi, C.; Rizzini, F.; Gambuti, A.; Moio, L.; Chkaiban, L.; Tonutti, P. Phenol Compound Metabolism and Gene Expression in the Skin of Wine Grape (Vitis Vinifera L.) Berries Subjected to Partial Postharvest Dehydration. Postharvest Biology and Technology 2012, 67, 102-109, doi:10.1016/j.postharvbio.2012.01.002.

63. 63. Versini, G.; Schneider, R.; Carlin, S.; Depentori, D.; Nicolini, G.; Serra, A.D. Characterisation of Some Northern Italian PassitiWines through Aroma and Stable Isotope Analyses.; 1999.

64. 64. R. Di Stefano, G. Maggiorotto, S. Gianotti. Transformation of nerol and geraniol induced by yeasts (Italian). Rivista di Viticoltura e di Enologia 1992, 45, 43

65. 65. S. Maicais, J. J. Mateo. Hydrolysis of terpenyl glycosides in grape juice and other fruit juices: a review. Appl. Microbiol. Biotechnol. 2005, 67, 322.)

66. 66. Guth, H. (1997). Quantitation and sensory studies of character impact odorants of different white wine varieties. Journal of Agriculture and Food Chemistry, 45, 349-354)

67. 67. Delfini, C.; Gaia, P.; Bardi, L.; Mariscalco, G.; Contiero, M.; Pagliara, A. Production of Benzaldehyde, Benzyl Alcohol and Benzoic Acid by Yeasts and Botrytis Cinerea Isolated from Grape Musts and Wines. Vitis -Geilweilerhof- 1991, 30, $253-263$.

68. 68. Rizzini, F.M.; Bonghi, C.; Tonutti, P. Postharvest Water Loss Induces Marked Changes in Transcript Profiling in Skins of Wine Grape Berries. Postharvest Biology and Technology 2009, 52, 247-253, doi:https://doi.org/10.1016/j.postharvbio.2008.12.004.

69. 69. Santonico, M.; Bellincontro, A.; Santis, D.; Natale, C.; Mencarelli, F. Electronic Nose to Study Postharvest Dehydration of Wine Grapes. Food Chemistry 2010, 121, 789-796, doi:10.1016/j.foodchem.2009.12.086. 